\title{
EL DERECHO INTERNACIONAL ECONÓMICO. APUNTES PARA UNA CRÍTICA CONTEMPORÁNEA
}

\author{
David ENRÍQUEZ*
}

RESUMEN: El objeto del presente artículo es centrar al derecho internacional económico como disciplina jurídica y revisar el estado actual de tres bloques de perspectivas críticas sobre él: axiológica, humanística y de desarrollo. Se argumenta la necesidad de superar los contenidos económicos de los instrumentos formales en la materia, para imprimir en ellos valores universalmente aceptados que fomenten la calidad de vida de las personas.

ABSTRACT: The purpose of the present paper is both, to centre International Economic Law as a juridical discipline, and to review its status from three clusters of critical perspectives: axiology, humanism and development. The paper argues the necessity of surpassing the formal contents of the instruments on the field, aiming to impart them with universally accepted values that may improve people's quality of life.

RÉSUMÉ: L'objectif de cet article est de situer le droit internationale economique comme une discipline juridique et reviser la situation actuelle de trois blocs de perspectives critiques pour lui: axiologique, humaniste et de developpement. Il est necessaire d'aller au delá des contenus economiques des instruments formels de la matiére, pour imprimer en eux des valeurs acceptées universellement afin d'encourager la qualité de vie des personnes.

* Doctor en derecho. Investigador nacional nivel 1 (SNI) e investigador titular del Instituto Panamericano de Jurisprudencia (UP). Representante del gobierno mexicano (SCT) ante la OMI, los FIDAC, la OIT, la CNUDMI, la OMC, la OCDE y la APEC, entre otros organismos internacionales. El contenido del presente artículo es responsabilidad exclusiva de su autor; por lo tanto, no debe ser entendido como la posición oficial del gobierno mexicano. 
SUMARIO: I. Introducción. II. El DIE: consideraciones conceptuales y tendencias. III. Perspectivas críticas al DIE. IV. Comentarios finales.

\section{INTRODUCCIÓN}

La agenda del derecho internacional económico se compone de temas que no escapan a la realidad del común de las personas. En este sentido, en el seno de la Organización Mundial del Comercio se negocia día con día la liberalización de productos básicos; en las oficinas del Banco Mundial se estructuran las condiciones crediticias para proyectos de infraestructura hospitalaria; o en el Programa de las Naciones Unidas para el Desarrollo se coordinan los esfuerzos para atenuar la mortandad infantil. Así pues, a pesar de su aparente nomenclatura de altas esferas diplomáticas, el derecho internacional económico toca hoy más que nunca, la realidad económica y social de cada persona.

En este contexto, el objeto de este artículo es en primer lugar, centrar la disciplina dentro del maremagnum del derecho - en especial con relación al derecho internacional público-; y en un segundo paso, revisar el estado actual de las perspectivas críticas, desde las cuales deben valorarse sus fuentes. Valga una breve explicación sobre el objeto pretendido. En nuestra opinión, los procesos de liberalización, las condiciones crediticias y las estrategias de desarrollo — ejemplos del párrafo anterior-, entre otras cuestiones, no pueden ya ser entendidos como fenómenos económicos aislados de una valoración plural. El sentido de este artículo pues, es esbozar las perspectivas desde las cuales este ejercicio puede realizarse.

De esta forma, el artículo se encuentra segmentado en dos secciones. La primera analiza al derecho internacional económico como objeto de estudio especializado del derecho internacional público. En dicho epígrafe, se proponen una serie de consideraciones conceptuales y se esbozan las tendencias en el campo académico y en la práctica contemporánea de las relaciones internacionales.

La segunda sección busca practicar una revisión de las perspectivas desde las cuales deben analizarse los instrumentos de la disciplina. Para propósitos académicos, hemos agrupado estas perspectivas en tres distintos bloques: axiológicas, humanísticas y de desarrollo sustentable. A modo de conclusión, proponemos algunas ideas sobre la participación 
que desde nuestra óptica, debe tener el académico en el quehacer de esta apasionante rama del árbol del derecho.

\section{EL DIE. CONSIDERACIONES CONCEPTUALES Y TENDENCIAS}

\section{Consideraciones conceptuales}

Sin pretender entrar aquí en un debate conceptual sobre el derecho internacional económico (DIE), podemos entenderlo, para propósito de este artículo, como una disciplina especial del derecho internacional público (DIP), que tiene por objeto la regulación de los intercambios económicos entre los sujetos de DIP. Sin embargo, esta definición parece simplista si no se tiene en cuenta la batería de complicaciones conceptuales propias del DIE. El objeto de este primer epígrafe es precisamente, tener en cuenta la complejidad para delimitar sus fronteras: qué es y qué no es DIE. ${ }^{1}$

Como indica Francis Botchway, a pesar de que la comprensión de los contenidos del DIE tiene antecedentes de siglos atrás, no fue sino hasta la segunda mitad del siglo XX que éstos han sido articulados de modo sistemático en torno a una disciplina especializada, aunque inmersa en el DIP. Sin embargo, una serie de contenidos aparentemente residuales como la regulación monetaria, la transferencia de tecnología, los efectos migratorios y laborales de los flujos económicos, el derecho al libre comercio, entre otros muchos, no se consideraban componentes tradicionales ni del DIP ni del derecho internacional privado (DIPr). ${ }^{2}$

El origen del problema en la clasificación de los elementos, hoy propios del DIE, se debió a la tradicional separación entre el DIP y el DIPr.

1 Véase Seidl, Ignaz, International Economic Law, Dordrecht, Kluwer, 1999, p. 1; Qureshi, Asif, Perspectives in International Economic Law, La Haya, Kluwer, 2002, pp. 9 y ss.; Bhandari, Jagdeep, Economic Dimensions in International Law, Cambridge, Cambridge University Press, 1997, p. 1; Bronckers, Marco, New directions in International Economic Law, La Haya, Kluwer, 2000, p. 101; Gilpin, Robert, The Political Economy of International Relations, Princeton, Princeton University Press, 1987, p. 8; Lowenfeld, Andreas, International Economic Law, Nueva York, Oxford University Press, 1997, p. 3; Becerra, Manuel, Derecho internacional público, México, UNAM, IIJ, 1991, pp. 9 y ss.; Seara, Modesto, Derecho internacional público, México, Porrúa, 1993, pp. 65 y ss.; Sepúlveda, César, Derecho internacional, México, Porrúa, 1991, pp. 78 y ss.

2 Botchway, Francis, "Historical Perspectives of International Economic Law", en varios autores, Perspectives..., cit., pp. 309 y ss. Véase Malnczuk, Peter, "Globalization and the future role of sovereign states", en varios autores, International Economic Law with a Human Face..., cit., pp. 45 y ss.; Lowenfeld, Andreas, "International Economic Law...", cit., pp. 3 y ss. 
En efecto, mientras el DIP trataba únicamente las relaciones entre Estados; el DIPr cubría las relaciones entre personas de derecho privado de distinta nacionalidad. Con ello, parecía haber poco espacio para considerar factores distintos a estas categorías binarias.

Así, el rigor en la clasificación tuvo por consecuencia natural que cuestiones legales distintas a las tradicionales del DIP o del DIPr, provenientes de organizaciones intergubernamentales y otros foros internacionales a partir del fin de la Segunda Guerra Mundial, quedaran o bien excluidas de toda clasificación; o bien adscritas con cierto forcejeo académico. ${ }^{3}$ Es en estos espacios estrechos y en ocasiones, poco ortodoxos, que el DIE fue buscando su propia sistematización dentro del DIP.

En el DIE confluía desde entonces, no sólo factores de índole económica, sino también figuras ambientales y temas de derechos humanos, que requerían de aceptación, pero también de auténtica compatibilidad axiológica y jurídica. En todo caso, la evolución de los primeros años del DIE fue más pragmática que académica, pues respondía más a intereses y necesidades reales de solución de problemas y concreción de proyectos internacionales de sustento financiero, que a la lógica universitaria de nomenclaturas y clasificaciones.

Si bien la disputa entre clasificar al DIE en el entramado del DIP o en el propio del DIPr, parece haber quedado ampliamente superada por el pragmatismo, debemos al menos distinguir dos tendencias — cada vez más tenues y de difícil delimitación - entre los autores que argumentan en pro o en contra. La justificación por apuntalarlo en el edificio del DIP suele inspirarse en la cohesión que sus figuras parecen tener dentro del sistema general del DIP. ${ }^{4}$ Ello en atención a que los sujetos y las fuentes

3 Véase Seidl, Ignaz, International Economic Law..., cit., pp. 3 y ss.; Bhandari, Jagdeep, Economic Dimensions in International Law..., cit., pp. 3 y ss.; Bronckers, Marco, New directions in International Economic Law..., cit., p. 101; Gilpin, Robert, The Political Economy of International Relations..., cit., p. 8; Diez de Velasco, Manuel, Las organizaciones internacionales, Madrid, Tecnos, 2003, pp. 37 y ss.; Seara, Modesto, Derecho internacional público..., cit., pp. 25 y ss. Entre los ejemplos que parecían quedar fuera del espectro natural de ambas disciplinas se encontraban las relaciones comerciales entre entidades de la administración pública de distintos Estados. Así, a pesar de que la naturaleza de la relación fuera mercantil, el tratamiento solía ser iuspublicista, con los problemas prácticos de negociación y celebración de contratos que esto implicaba, por no quedar claramente delimitados los ámbitos de aplicación tanto del DIP como del DIPr. De igual forma, la regulación de organismos internacionales de índole económica como el FMI o el BRD se consideraban ajenas a las categorías clásicas propias del DIP o del DIPr.

4 Los temas tradicionales del DIP han sido normalmente: (i) fuentes; (ii) sujetos; (iii) derecho de los tratados; (iv) dominio espacial de los Estados; (iv) solución pacífica de conflictos; (v) 
del DIE siguen siendo principalmente Estados y tratados internacionales, respectivamente.

Por su parte, quienes pretenden encasillarlo en el campo del DIPr parecen querer dotar a éste de nuevos contenidos sustantivos, ya que dado el proceso de especialización de sus antiguas áreas de interés en disciplinas especiales del derecho, parece haber quedado hoy restringido casi exclusivamente al llamado derecho conflictual. ${ }^{5}$

Además, una serie de figuras que en ocasiones buscan encuadrarse en el DIPr - el comercio de bienes y servicios, las inversiones, la energía, las telecomunicaciones, etcétera - tienen una evidente orientación económica y un profundo giro de regulación pública nacional e internacional. Esta situación ha llevado a que la terminología propia del DIPr antes usada para estos sectores quede rebasada, para utilizar en su lugar, referencias generales de carácter internacional y desde luego, de naturaleza económica. ${ }^{6}$

Una razón más para evitar incluir al DIE dentro del DIPr consiste en advertir que la eliminación de barreras al comercio internacional, no incide solamente en el ámbito privado. Por el contrario, es cada vez más común encontrar posturas de naturaleza auténticamente iuspublicista sobre el comercio internacional.

Así, encontramos por una parte, a quienes abogan por el derecho al comercio libre de toda restricción gubernamental; y por la otra, a quienes defienden la dimensión de los derechos humanos, el buen gobierno institucional, las condiciones laborales y la eliminación del trabajo infantil, la

responsabilidad internacional; (vi) derecho de la guerra. Véase en general los índices en Brownlie, Ian, Principles of Public International Law, Oxford, 1999; Pastor, José, Curso de derecho internacional público, Madrid, 1999.

5 Véase en general los contenidos reconocidos hoy en día del DIPr en Pereznieto, Leonel, Derecho internacional privado, México, OUP, 1999; Arellano, Carlos, Derecho internacional privado, México, Porrúa, 1974; Batiffol, Henri y Lagarde, Pierre, Droit international privé, París, LGD, 1975; Carrillo, José, Derecho internacional privado, Madrid, Tecnos, 1971; Contreras, Francisco, Derecho internacional privado, México, Harla, 1994; Fernández Rozas, José, Curso de derecho internacional privado, Madrid, Civitas, 1991; Vázquez, Fernando, Nuevo derecho internacional privado, México, Themis, 1990. Como podrá advertirse los temas centrales del DIPr continúan siendo: (i) la nacionalidad, (ii) la condición jurídica del extranjero — que parece tener cada vez más una especialidad propia en el derecho migratorio-; (iii) y el derecho conflictual como piedra angular de la disciplina.

6 Véase, en general, Sornarajah, M., The International Law of Foreign Investment, Cambridge, CUP, 1994; Jackson, J., Legal Problems of International Economic Relations, N. Y., West Publishing, 1995; Botchway, Francis, op. cit., p. 310. 
protección al ambiente, la protección de la diversidad cultural y religiosa, las cuestiones de género, etcétera.

Como podrá advertirse, el DIE, si bien tiene un núcleo operativo en actividades económicas llevadas a cabo mediante un intrincado número de relaciones de derecho privado entre personas de distintos Estados - componente DIPr - se encuentra revestido de regulación propia del derecho público, y afectado además, por la dinámica de las relaciones internacionales - componente de DIP-.

En este contexto, aunque no propugnamos por la autonomía del DIE, y en cambio aceptamos su relativo acomodo en el DIP - por las connotaciones a las que hasta aquí hemos aludido - nos parece que sus componentes mixtos deben ayudar a ver, con escepticismo, todo intento por fijarlo de modo inamovible a cualquiera de las dos categorías tradicionales del estudio internacional. ${ }^{7}$

\section{Tendencias}

La historia del DIE como disciplina jurídica fluye en paralelo a la de la institucionalización y globalización económicas, pues el DIE como disciplina académica, es en buena medida la sistematización de los instrumentos que dotaron de estructura legal a organismos internacionales de especialidad económica, y de aquellos que formalizaron las variadas formas de intercambios económicos entre Estados $-\mathrm{y}$ su incidencia en los sujetos de derecho privado-.

Si bien no tenemos la intención de proponer aquí un estudio de la institucionalización de la economía mundial, sí parece pertinente retomar algunos de los hitos que han marcado el estado actual de la disciplina y posiblemente, sus siguientes pasos: la aceptación de los principios rectores del libre mercado tras el fin de la Guerra Fría; la regionalización de bloques económicos; y las contratendencias a la globalización económica.

El final de la Guerra Fría tuvo como consecuencia para el DIE la franca desaparición o bien la suspensión indefinida del debate - $\mathrm{y}$ la consecuente producción de instrumentos internacionales - de al menos tres importantes figuras — auténticas columnas ideológicas de su tiempo-

7 En el contexto nacional, véase su ubicación en Witker, Jorge, Curso de derecho económico, México, UNAM, IIJ, 1989, pp. 18 y ss. 
acuñadas a lo largo de la década de los sesenta y setenta principalmente. Nos referimos al nuevo orden económico mundial, el derecho al desarrollo y el principio de la soberanía permanente sobre los recursos naturales. ${ }^{8}$

Las tres columnas fueron instrumentadas en documentos que, como se revisará en este trabajo, tienen la jerarquía de fuente subsidiaria de DIP, y fueron abanderadas por países en desarrollo; de manera especial por el llamado Grupo de los 77, del cual México no solamente formó parte, sino incluso protagonizó especialmente en la década de los setenta. ${ }^{9}$

A raíz de la polarización ideológica de la segunda mitad del siglo $\mathrm{XX}$, una serie de países en desarrollo, incluyendo los del bloque soviético europeo, criticaron el imperialismo económico que se intentaba imponer a través de las instituciones del Bretton Woods. El derecho recogió esta lucha ideológica en el seno de la ONU, a través de instrumentos declarativos fuente de DIE, en materia de derechos civiles y políticos - de tinte capitalista - y de derechos económicos y sociales — de inclinación socialista - ${ }^{10}$ Las diferencias en materia de ideología económica llevaron pues, a la edificación de los tres paradigmas citados que, naturalmente quedaron contenidas en el DIE de la época.

Sin embargo, el desmoronamiento de la cortina de hierro significó un movimiento pendular hacia los principios del libre mercado - sintetizados en el llamado Consenso de Washington-. El intervencionismo estatal aclamado dos décadas antes no solamente era mal visto bajo el nuevo acuerdo, sino que áreas económicas tradicionalmente exclusivas para el

8 Bedjaoui, M., Towards a new international economic order, París, UNESCO, 1979; Ropke, W., Economic Order and International Law, 1954, vol. 86, Curso de Colección, pp. 207 y ss.; Seidl, Ignaz, Sovereignty and Economic Co-existence, Clunet 86, 1959, pp. 105 y ss.; Wealde, W., Permanent Sovereignty over Natural Resources: recent development in the mineral sector, Natural Resources Forum, 7 1983, pp. 249 y ss.

9 Véase, en general, Larson, Deborah, Anatomy of mistrust: US-Soviet relations during Cold War, Ithaca, Cornell University, 1997; Hunter, Allan, Rethinking the Cold War, Philadephia, Temple University, 1998; Powaski, Roland, La Guerra Fría: EUA y la Unión Soviética 1917-1991, Barcelona, España, Crítica, 2000.

10 Entre las principales resoluciones de la Asamblea General de la ONU sobre las columnas del DIE de las dos décadas mencionadas, véase UN Doc. A/C.3/34/SR.24-30 y ss.; UN Doc. E/CN.4/SR.1389 y ss. (1977); GA Res. 174, 35 UN GAOR (19080); GA Res. 1803 (XVII) (1962). Véase, además, Walde, T., A réquiem for the New International Economic Order: The rise and fall of paradigms of International Economic Law (1997) (1-2), CEPML\&P Journal; Connelly, J., In Search of the Unicorn: Jurisprudence and Politics of the Right to Development (1985) CWILJ, pp. 169-203. 
Estado, como la energía y las telecomunicaciones experimentaron profundos procesos de privatización en todo el mundo en desarrollo y en las economías en transición. Las entidades financieras internacionales - como se analiza aquí mismo- harían su parte en esta nueva forma de entender la economía mediante la creación y seguimiento de programas de ajuste estructural.

La cancelación de los tres paradigmas ideológicos, dio pie a un segundo hito - vigente aunque sujeto a revisión - en los contenidos del DIE. Nos referimos a la regionalización de bloques económicos, que en el caso de algunas regiones ha sin duda rebasado la dimensión económica. Así, con diversos grados de evolución de acuerdo a sus propias características regionales y culturales, y por consiguiente niveles diferenciados de cohesión, podemos hablar hoy en día de la UE, del TLCAN, de la APEC o del Mercosur entre otros varios. Salvo el caso de la UE - cuyo antecedente data de más de medio siglo-, el resto de los procesos de integración no cumplen todavía dos décadas de existencia; y otros como el ALCA, apenas luchan por salir a la luz. ${ }^{11}$

Un tercer hito en la historia reciente del DIE es el flujo en contracorriente sobre el proceso de globalización. Tras la presión de las ONG en la OMC y el BM durante la última década, los foros sociales tienen cada vez más presencia en las discusiones multilaterales. De hecho, los nuevos instrumentos del DIE sobre desarrollo sustentable, no podrían comprenderse, de no ser por la participación crítica y continua de la sociedad civil, mediante estas organizaciones.

En estos dos epígrafes hemos hecho un breve recuento de los acomodos del DIE como disciplina relacionada con el DIPr y enmarcada en el DIP con un cierto grado de especialidad. Hemos reconocido algunos de sus campos de acción y señalado los hitos que han transformado sus contenidos a lo largo de medio siglo. Sin embargo, ni la exploración de su desarrollo como rama del derecho ni sus diferencias con el DIPr y su relación estrecha con el DIP; ni tampoco las explicaciones de la doctrina consultada, parecen ser suficientes para determinar qué es el DIE y hacia dónde habrá de evolucionar con el paso del siglo XXI.

Bajo nuestro criterio, el análisis académico presenta dos dificultades en la determinación del objeto material de estudio del DIE; así como un

11 Véase Witker, Jorge (coord.), El Área de Libre Comercio de las Américas (ALCA), México, UNAM, IIJ, 2004, pp. IX y ss. 
problema adicional relativo a su interacción con otras ciencias sociales. Con el fin de exponer nuestra posición es necesario desarrollar brevemente los tres expedientes que anunciamos. ${ }^{12}$

El primer binomio responde por una parte a que el DIE tradicionalmente ha considerado temas de natural enclave iusprivatista, pues tiene que ver con relaciones jurídicas entre sujetos de derecho privado, que son los principales actores en la economía internacional. En este campo, se han considerado incluidos temas de finanzas internacionales o de responsabilidad en el comercio internacional, en el transporte de mercancías, etcétera.

Sin embargo, al mismo tiempo se ha pretendido incorporar en su agenda aspectos que responden a relaciones subordinación; esto es, al derecho público. En este ámbito, podemos mencionar los tópicos fiscales internacionales, la dimensión internacional de la propiedad industrial, la protección internacional del ambiente, la dimensión económica de los derechos humanos y la libertad de empresa; así como actividades económicas sujetas a fuerte regulación pública como los energéticos o las telecomunicaciones.

Por otro lado, el problema de interacción con otras áreas de las ciencias sociales se ubica en reconocer que algunos de los temas de mayor peso específico en la agenda del DIE - como la desregulación del comercio internacional de bienes y servicios a través de la OMC, el financiamiento público internacional mediante el BM y el FMI, o las estrategias hacia el desarrollo sustentable del PNUD, entre otros tópicos- son de la mayor sensibilidad social hoy en día. Este grado de sensibilidad de las $\mathrm{ONG}$, medios de comunicación y sociedad civil en general, hacen que los contenidos del DIE parezcan altamente dinámicos, y que queden envueltos en una discusión interdisciplinaria que escapa al solo campo del derecho. ${ }^{13}$

Pues bien, una vez reconocidas las dificultades en determinar qué es y cuáles son los linderos del DIE, pasemos ahora a señalar cuándo un de-

12 Cfr. Seidl, Ignaz, op. cit., pp. 3 y ss.; Pinto, M., International Economic Law with Human Face..., cit., pp. 13 y ss.; Lowenfeld, Andreas, op. cit., pp. 7 y ss.

13 Rodrik, Dani, "Has globalization gone too far?", en varios autores, The Globalization Reader, Londres, IOP, 2003, pp. 224 y ss.; véase Stiglitz, Joseph, “Globalism's Discontents”, en varios autores, Globalization Reader..., cit., pp. 201 y ss.; Jackson, John, International Economic Law in times that are interesting, JIEL (2000) pp. 3-14; Deardorff, Alan, "The Economics of Government Market Intervention”, en varios autores, New directions in International Economic Law..., cit., pp. 71 y ss. 
terminado tema debe entrar realmente en el terreno de preocupación del DIE. De lo contrario, corremos el riesgo de creer que el hecho de que un determinado tema, que sea de naturaleza económica y de dimensión económica, debe ser reconocido por ese solo hecho, como dentro de la agenda del DIE. Esto sería, desde nuestro punto de vista, incorrecto.

Para evitar que cualquier aspecto de matiz internacional y económico, sea objeto del DIE, es necesario formular al menos las siguientes preguntas, cuyas respuestas deben ser positivas, todas al mismo tiempo: ¿es el tema auténticamente económico?; ¿se encuentra el tema regulado bajo una relación jurídica de subordinación de una persona de derecho privado a una de derecho público; o de coordinación entre sujetos de derecho público?; ¿es el tema regido por fuentes formales de carácter internacional?; ¿es la especialidad del tema reconocida como una disciplina distinta del DIE?

De la solución de estas cuatro simples preguntas podremos caer en cuenta que hay una serie de tópicos que aunque tengan un cierto vínculo o una perspectiva crítica del DIE, no son por ello, DIE. Es así como la tendencia académica del DIE en el siglo XXI, parece ser a la redistribución de sus contenidos hacia las materias que deben en realidad pertenecer.

Sin embargo, seguirá siendo tarea institucional de la universidad y de quien diseñe el curso de DIE la decisión sobre la perspectiva y la profundización que se le pretenda ofrecer. En este sentido, los cursos pueden centrarse en los contenidos propios del DIE; o bien, en contenidos de derecho privado que por alguna razón tengan conexión con el DIE .14

La práctica internacional del DIE en cambio, no necesariamente gozará de los compartimentos organizados del mundo académico. Seguirá cada vez con mayor intensidad influida por la opinión de las ONG y los medios de comunicación, de acuerdo a los vaivenes y críticas sobre la globalización. Parece evidente, que lo que antes parecía tener una dimensión exclusivamente económica —otorgamiento de créditos internacionales para el desarrollo, negociación de liberalización de comercio de bienes y servicios, acuerdos sobre inversiones, etcétera - no podrá escapar de la necesaria revisión social mediante consideraciones de derechos humanos, de protección al ambiente, de equidad de género, y otras más. 


\section{PERSPECTIVAS CRÍTICAS DEL DIE}

\section{Justificación}

Con lo que hasta aquí hemos avanzado, nos parece pertinente trazar un nuevo mapa dentro del cual podamos identificar los ángulos desde los cuales se critica y nutre al DIE; los sujetos que inciden en este ejercicio; y los intereses - económicos o de otra especie - que determinan la acción de cada sujeto en la crítica e influencia al DIE.

Parece que hacer un recuento de las perspectivas agrupadas bajo un criterio temático es tal vez una buena metodología, no solamente para comprender más cabalmente el DIE, sino para reconocer sus tendencias y las causas de éstas. En realidad, un ejercicio así permite conocer de manera articulada - y en cierto modo ecléctica- el universo de las fuentes reales que determinan los instrumentos formales del DIE. Por todo ello, nos parece justificable el estudio de una gama relevante de perspectivas. $^{15}$

Así pues, un estudio de las perspectivas hacia el DIE permite por una parte identificar su evolución y los factores que han incidido en él. Posibilita también conocer los distintos actores - públicos y privados- que lo afectan y sus intereses específicos como grupo de presión en la toma de decisiones. Y finalmente, ofrece elementos de evaluación de la disciplina en cuanto a su objeto, sus sujetos y su interacción con la economía global.

Antes de cerrar este breve apartado de justificación, nos parece prudente advertir, como lo hace Asif Qureshi, en el sentido de no perder de vista los intereses existentes en cada perspectiva; pues es claro que aquellos son claramente los guías de estas últimas. ${ }^{16}$ En efecto, la historia se ha encargado de desmentir que el DIE — en especial las agendas de organismos internacionales - está lejos de acercarse a una posición objetiva sobre los asuntos económicos.

15 La sistematización de las perspectivas en torno al DIE no ha sido una tarea fácil. En nuestra opinión, uno de los mejores esfuerzos de compilación de una serie de autores agrupados a partir de temas convergentes es el de Alif Qureshi de la Universidad de Manchester. Junto con otros textos, será el estudio específico de cada autor el que servirá como eje a esta sección. Véase Qureshi, Asif (ed.), Perspectives in International Economic Law, La Haya, Kluwer, 2002.

16 Qureshi, Asif, "Perspectives in International Economic Law. An eclectic approach to international economic engagement", en varios autores, Perspectives..., cit., pp. 11 y ss. 
Son en realidad las agendas de intereses múltiples de los sujetos del DIE - ya sean países, ONG, empresas multinacionales, grupos de presión e individuos - más influyentes en la negociación las que incluyen o excluyen un tema y su tratamiento. Sin embargo, es justo reconocer también, que estas agendas son dinámicas y cada vez más susceptibles de verse obligadas a llegar a puntos razonables de negociación que, al fin y al cabo, ofrecen mayores posibilidades de un auténtico espíritu objetivo.

Como en cualquier ejercicio de categorización, se corre el riesgo de caer en alternativas arbitrarias. En el entendido que asumimos ese riesgo, nos parece que una buena alternativa para ubicar los puntos de vista bajo un criterio temático - y parcialmente regional — es la de considerar para fines didácticos tres grandes bloques: perspectivas axiológicas, perspectivas humanistas, y perspectivas de desarrollo sustentable. Desde luego, parte de la riqueza del debate está en evitar que la metodología de la exposición construya compartimentos estancos entre uno y otro bloque.

Con dicha advertencia metodológica preliminar, podemos considerar el estudio de lo que una variedad de autores e instituciones - de igual número de perfiles académicos e intereses - opina en este complejo mapa del DIE y la economía global. De igual manera es importante alertar, que como es natural, no buscamos agotar cada una de los bloques de perspectivas citado, sino tan sólo destacar el estado de las cosas en el debate doctrinario de la crítica al DIE. A ello, adicionaremos nuestra posición respecto, tanto a partir de nuestra investigación documental, como a raíz de nuestra participación como representante de México ante una serie de organismos internacionales productores de DIE.

\section{Perspectiva axiológica}

Diversos académicos, entre los cuales destacan Thomas Franck, John Rawls y Robert Cryer han puesto en evidencia la necesidad de confrontar los contenidos y tendencias del DIE con los valores universales de la justicia y la equidad. Para estos autores, el derecho internacional ha llegado a una etapa post-ontológica, de modo que el dinamismo debe ahora centrarse en la generación de un marco teórico a partir del cual la disciplina 
pueda evaluarse, teniendo como eje direccional precisamente estos valores. ${ }^{17}$

Verificar su vigencia en el derecho internacional en general y en el DIE en particular, implica en primer lugar, analizar la medida en la cual las normas satisfacen una justificada distribución de costos y beneficios entre los partícipes. En segundo, la medida en la cual estos mismos partícipes del sistema perciben que las normas son creadas y aplicadas de modo correcto. Así pues — en palabras de Franck-, la percepción general de justicia de la norma implica a su vez la percepción de la institución a la que ésta aplica, así como la rectitud en la efectiva gestión y aplicación de tal institución. Así la percepción de estos valores, en buena medida depende también del equilibrio en la distribución de poderes dentro de la estructura institucional del proceso de creación y aplicación de la norma. ${ }^{18}$

Con ello, los valores a los que aquí hacemos referencia cuentan tanto con un elemento sustantivo, como con uno adjetivo o de procedimiento. Veamos las dos caras de esta moneda axiológica en la crítica de Cryer, primero revisando el aspecto adjetivo y más tarde el sustantivo. ${ }^{19}$ La porción adjetiva de la pregunta sobre la vigencia del valor de la justicia y la equidad en el DIE se manifiesta en la elaboración e interpretación de las normas, y no en su contenido de fondo; se concreta en la legitimidad de la norma. ${ }^{20}$ De acuerdo a la doctrina de Franck, en el ámbito del derecho internacional, la legitimidad de la norma deriva del reconocimiento entre Estados como soberanos e iguales, así como en su derecho para expresarse libremente, e incluso limitar su soberanía a partir del propio consentimiento, de modo que la norma pactada en el ámbito de la comunidad internacional sea válidamente aplicable.

17 Véase, en general, Franck, Thomas, Fairness in International Law and Institutions, Oxford, OUP, 1995; Cryer, Robert, "Franckian Fairness and International Economic Law", en varios autores, Perspectives..., cit.; Rawls, John, A Theory of Justice, Oxford, OUP, 1999. De igual manera, véase en cuanto a las consideraciones generales de la filosofía del derecho: Wilheim, Leibniz, Tres ensayos: el derecho, la equidad, la justicia y la sabiduría, trad. de Eduardo García Máynez, México, UNAM, Centro de Estudios Filosóficos, 1960, pp. 5 y ss.; Raz, Joseph, La autoridad del derecho. Ensayos sobre derecho y moral, trad. de Rolando Tamayo y Salmorán, México, UNAM, IIJ, 1985, pp. 207 y ss.; Tamayo y Salmorán, Rolando, El derecho y la ciencia del derecho. Introducción a la ciencia jurídica, México, UNAM, IIJ, 1986, pp. 139 y ss.

18 Franck, Thomas, Fairness..., cit., p. 173.

19 Cryer, Robert, op. cit., pp. 211 y ss.

20 Franck, Thomas, The Power of Legitimacy among Nations, Oxford, OUP, 1990, pp. 26 y ss. 
Desde luego, existen ulteriores restricciones a la libertad soberana del Estado como el uso de la fuerza, las medidas económicas coercitivas o incluso algunas obligaciones de naturaleza consuetudinaria, que aún siendo naturalmente contrarias al consentimiento de un determinado país, se basan en las normas básicas de actuación entre Estados. ${ }^{21}$

Para considerar una norma como legítima, la doctrina de Franck sugiere tener presentes cuatro criterios elementales: determinación, validación simbólica, coherencia y adherencia. El criterio de determinación significa que las normas no sean substancialmente vagas. La validación simbólica implica que todos los participantes —Estados soberanosreafirmen frecuentemente su compromiso de continuar con las normas en cuestión. El criterio de la coherencia establece que la misma categoría de normas aplique a la misma categoría de casos, y al mismo tiempo indica que tal categoría de normas sea congruente con el derecho internacional en general. Finalmente, el criterio de la adherencia, significa que los Estados manifiestan una predisposición a cumplir normas que ya están siendo cumplidas por otros Estados. ${ }^{22}$

En suma, la manera en la que las instituciones crean, administran y hacen cumplir la norma tiene una estrecha vinculación con la percepción de los valores que comentamos. Desgraciadamente, el corazón del sistema mismo de las Naciones Unidas es un ejemplo de percepción contraria de estos valores. En efecto, la estructura misma en la membresía del Consejo de Seguridad de la ONU — algunos de cuyos miembros no son elegidos por la asamblea - hace que la percepción en la creación, administración y cumplimiento de las normas sea negativa. ${ }^{23}$

Pasemos ahora al elemento sustantivo - o de fondo - de la norma para tener un contexto completo, ante el cual contrastemos la consecu-

21 Véase, por ejemplo, el art. 52 de la Convención de Viena sobre el Derecho de los Tratados. Sin duda, la regla general del consentimiento por el Estado soberano no es tan sencilla como se imaginaría, como es el caso de la aplicación del derecho internacional consuetudinario a países de reciente constitución.

22 Franck, Thomas, The Power..., cit., pp. 27 y ss.

23 Desde finales del 2004, el secretario general de la ONU ha recibido el informe de un comité de expertos con miras a una reforma de la organización, en la cual, el Consejo de Seguridad se vería parcialmente alterado. Sin embargo, a pesar de que continua la presión internacional en no modificar la estructura del consejo $-\mathrm{y}$ sí en cambio probablemente ampliar su número de miembros permanentes - existen propuestas interesantes basadas en la elección no de países sino de individuos tanto en el Consejo de Seguridad como en otros órganos del sistema. Véase, por ejemplo, Held, David, Democracy and the Global Order: From the Modern State to Cosmopolitan Governance, Oxford, Polity Press, 1997. 
ción o no de los valores de justicia y equidad en el DIE. Por naturaleza, este segundo elemento se basa en los resultados efectivos del proceso normativo de la institución; tiene así que ver con la materia misma a regular. En la doctrina de Franck aparecen dos argumentos que justifican la importancia del elemento sustantivo: uno pragmático o utilitarista y el otro, deontológico.

El primer argumento radica simplemente en que la gente se inclina generalmente más en cumplir con las normas que le parecen justas - desde luego, este argumento no necesariamente tiene toda la fuerza fáctica que se querría-. El argumento de orden deontológico es relevante, pues en términos generales la gente considera que actuar de modo justo es algo bueno. Esto es, el ciudadano medio tiene un sentido de justicia, aunque no necesariamente exista un consenso sobre el debate moral en torno a ella. Así, las democracias liberales —o sus grupos de presióntienden a hacer algún tipo de evaluación sobre la justicia de los actos, tanto al nivel nacional como al internacional.

En este contexto de elementos — sustantivo y adjetivo - y de argumentos relacionados — pragmáticos y deontológicos - en torno a la pregunta sobre la vigencia de los valores universales de justicia y equidad, en la creación y aplicación normativa de las figuras del DIE, es que los autores se aúnan en coincidir que es precisamente la equidad lo que supone el valor más refinado en la teoría de la justicia del derecho internacional. Así, la equidad se convierte en un corrector de la justa (dar a cada uno lo suyo en la fórmula latina) y estricta aplicación de las normas jurídicas, cuyas características naturales - principalmente generalidad abstracción - ${ }^{24}$ suponen, en ocasiones la producción de situaciones intolerables por su desequilibrio ético.

Hasta aquí pues las disquisiciones sobre los componentes e interacción de los valores éticos esperados en el proceso de creación normativa y en la sustancia de ésta. Contrastemos ahora brevemente la vigencia - $\mathrm{O}$ su ausencia - de éstos en el sistema económico internacional, a través de las algunas instituciones propias del DIE.

Pues bien, debe reconocerse que al fallar el sistema económico mundial en la generación de satisfactores compensatorios a las desventajas creadas con el proceso de globalización, resulta evidente que los valores de la justicia y la equidad quedan minados por las políticas instrumenta- 
das al interior de las instituciones y mediante los procesos propios del DIE. Así, el ángulo sustantivo de las normas de DIE - los contenidos mismos de la disciplina - han sido ajenos — incluso contrarios - a tomar decisiones e implementar acciones que manifiesten los valores que hemos expresado.

Entre las grandes omisiones que avalan esta contradicción entre los valores y la realidad del DIE a través de normas y políticas públicas de organismos como el Banco Mundial o la OMC se encuentran: la falta de una auténtica remisión de la deuda de los países menos desarrollados, la ausencia de edificación de un trato no-comercial que beneficie a los más pobres, la escasa transferencia de tecnología a costos razonables, la mínima utilización de recursos financieros mediante impuestos internacionales para el alivio de la miseria, mediante programas integrales de salud, alimentación y educación, etcétera. ${ }^{25}$

Desde luego, sería absurdo decir que no hay esfuerzos de la comunidad internacional por hacer frente a estas exigencias axiológicas, de urgente dimensión humanitaria. Sin embargo, de lo que hasta aquí hemos estudiado, el DIE como disciplina, parece estar todavía lejos de verse reflejado en los valores de la justicia y la equidad, pues sus principales actores - los Estados mediante sus gobiernos - no han querido dotarlo de tales contenidos.

Sin embargo, es más cuestionable aún reconocer que ya que en los regímenes democráticos son las sociedades las que eligen a sus gobiernos; y al no haberse éstos decidido por dotar de contenidos éticos efectivos a las normas y políticas de DIE, es claro que las sociedades que los han elegido, no han podido - o querido - obligarlos a ello, dado el costo, por insignificante que sean en comparación a la vida y bienestar de millones de seres humanos en la pobreza, de este ejercicio de nobleza y humanidad.

Si bien parece claro - y desolador - el panorama del elemento sustantivo de la norma del DIE, veamos su dimensión adjetiva. Esto es, exploremos si los valores que han servido como eje a este epígrafe se encuentran al menos, en el proceso de creación normativa del DIE. En

25 Como bien ha señalado el Nobel de Economía Amartya Sen, que el costo de la educación básica y la salud en los países en desarrollo es bajo ya que estos servicios son intensivos en mano de obra y los salarios en este tipo de países son pobres. Así, una cantidad relativamente baja de recursos podría generar enormes diferencias. Amartya, Sen, Development as Freedom, Nueva York, Random House, 2000, pp. 47 y ss. 
definitiva, se trata de saber quién y cómo tiene voz y voto en el diseño de normas y políticas públicas vinculadas al DIE. Desde la óptica de Thomas Franck es indispensable considerar dos niveles de participación: el nacional y el internacional. ${ }^{26}$

Por lo que al nivel nacional se refiere, es el juego democrático de la política de cada país lo que aumenta la probabilidad de que la norma de DIE - en sustancia y proceso - cuente con los valores de justicia y equidad. Es un hecho que por la jerarquía normativa de los tratados internacionales, el legislador y administrador público nacionales tienen un margen de maniobra restringido, pues deben incorporar y aplicar normas en cuyos procesos no necesariamente han estado involucrados.

Esta crítica es claramente aplicable al rol de organismos como el Banco Mundial y el FMI con relación a sus políticas de ajuste estructural para liberalizar las economías nacionales acreditadas. En efecto, para obtener la asistencia financiera necesaria, los países en desarrollo suelen tener la imposición de estos organismos, en aceptar sus criterios de buen gobierno, privatización, así como apertura comercial y de inversiones. Como valientemente han denunciado prestigiados académicos, son los órganos de gobierno del país los que deben determinar su política económica y no los financieros - públicos o privados - que otorgan los créditos. $^{27}$

Así, la necesidad apremiante de un país por préstamos de subsistencia de corto plazo - incluso para refinanciar deudas saldadas varias veces - no otorga desde el punto de vista ético, derecho alguno a los organismos internacionales a imponer condiciones que no solamente exceden las características de un crédito; si no que además han demostrado ampliamente su ineficacia y efectos permisivos.

Con ello, no es novedoso afirmar que en múltiples casos, han propiciado deterioros mucho más profundos tanto en las economías en general, como en los tejidos sociales por potenciar ante todo, la inequidad social. No se trata de cumplir bien o no el tratamiento "recomendado", sino la falta de legitimidad de los organismos financieros para imponer condiciones, que en todo caso deben ser externas a los contenidos de un crédi-

26 Franck, Thomas, Fairness..., cit., pp. 478 y ss.

27 Véase Feldstein, Martín, "Refocusing the IMF”, Foreign Affairs, 1998 (77-2) pp. 27 y ss.; Cryer, Robert, op. cit., pp. 229 y ss. 
to, y que solamente compete decidir a las instituciones democráticas de cada país.

Otra cuestión en debate referida al ámbito nacional sobre el proceso y la sustancia de los valores que hemos comentado en la norma de DIE, es que en la mayoría de los sistemas jurídicos el proceso de aprobación de un tratado y la posibilidad de incidir de fondo son francamente minúsculos, en comparación con los ejercicios equivalente en leyes nacionales, en las que la participación social de cada país es mucho más intensa desde el origen de la iniciativa.

Más aún, parece haber una clara tendencia en los tratados internacionales contemporáneos — no solamente de índole técnica- de segmentar los contenidos de modo tal, que algunos de ellos se actualicen en forma tácita. Si bien esto puede ser positivo para algunas materias, puede representar un creciente déficit democrático en decisiones muy relevantes, pues como hemos dicho, la jerarquía normativa de las disposiciones internacionales reduce el margen de maniobra tanto del legislador como del diseñador y ejecutor de políticas públicas en el país. ${ }^{28}$

Si el ámbito nacional es preocupante, el internacional es, en muchas de sus instituciones clave, manifiestamente contrario a la efectiva vigencia de los valores de la justicia y la equidad en el DIE. La democratización y el buen gobierno han sido valores altamente pregonados en especial por países desarrollados hacia las naciones en desarrollo. Sin embargo, estas máximas institucionales están lejos de ser una realidad en organismos como el Banco Mundial o el FMI, de los que ya hemos hablado. En efecto, no solamente es un privilegio de Estados Unidos de América y Europa Occidental la designación de sus altos funcionarios, sino que como la historia lo ha demostrado las agendas para-económicas de los más poderosos — principalmente Estados Unidos de Américahan estado presentes en las políticas y criterios de los organismos financieros. ${ }^{29}$ ¿Puede en este contexto considerarse que las instituciones, las normas y los procesos de DIE sean justas y equitativas?

28 Véase, en este sentido, Strange, Susan, "The declining authority of States", en varios autores, Globalization Reader..., cit.; Garrett, Geoffrey, "Partisan Politics in the Global Economy", en varios autores, Globalization Reader..., cit.; Rodrik, Dani, "Has globalisation gone too far?", en varios autores, Globalization Reader..., cit.; Annan, Kofi, "The role of the State in the age of globalisation", en varios autores, Globalization Reader..., cit.

29 Véase Brown, B., The United States and the politicisation of the World Bank, Nueva York, K. Paul, 1992. 
Si bien en otros foros internacionales como la OMC los privilegios antidemocráticos no son tan manifiestos como en los organismos financieros, sus métodos distan de respetar los valores objeto de este epígrafe. Así, los grupos "informales" de discusión, constituidos fundamentalmente por los países desarrollados suelen acordar con antelación las agendas - y sus contenidos - a ser después impuestas al resto de la comunidad internacional. El déficit democrático es evidente; y en consecuencia, las probabilidades de reconocer en la norma de DIE justicia y equidad, no solamente parecen remotas, sino tristemente, ilusas.

La participación de este autor en las delegaciones mexicanas ante diversos organismos internacionales generadores de DIE, ha permitido evidenciar cómo la única estrategia posible de negociación en el ámbito multilateral ante un tema de interés nacional, es primero que éste no sea insalvablemente perjudicial para los países desarrollados interesados; y segundo, contar con el apoyo manifiesto de dichos países. Esta exigencia de negociación y la necesidad de un "padrino desarrollado", aunque pueda considerarse una necesidad en el contexto diplomático, resulta francamente indigna desde el punto de vista de la práctica de los valores de la justicia y la equidad. ${ }^{30}$

Así pues, todo parece apuntar que la estructura misma del sistema multilateral - sea o no de entidades adscritas a las Naciones Unidasestá orientada a que los organismos no sean más que foros de mero trámite de legitimación automática "internacional" respecto de las agendas previamente acordadas por los países desarrollados clave. El reto titánico es reconocer abiertamente esta realidad intrínsecamente pervertida de la organización multilateral, y presionar con argumentos y liderazgo moral y diplomático para redefinir el sistema internacional, teniendo como fuente única la vivencia de los valores a los que hemos aludido.

\section{Perspectiva humanística}

\section{A. Consideraciones de derechos humanos en general}

Como señala Michael Addo, si bien la perspectiva de derechos humanos del DIE, por su propia naturaleza no puede compararse con sus si-

30 Como se ha indicado al inicio de este trabajo, la opinión es personal y no manifiesta la posición oficial de las dependencias gubernamentales mexicanas, en las cuales he estado adscrito como negociador. 
milares de índole estrictamente objetiva, se espera al menos que sus valores centrales sean reconocidos al desarrollar y aplicar las normas propias de la disciplina. En realidad la sinonimia de los derechos humanos con las nociones de libertad, justicia, rectitud, Estado de derecho, dignidad, equidad y solidaridad es tan sólida, que debiera ser tenida en cuenta por todo ámbito jurídico. Así, se convierte en un imperativo el que los valores propios de los derechos humanos cuenten con un puerto seguro en el DIE, ya que el rol cada vez más importante de esta disciplina es regular el complicado escenario económico de las relaciones internacionales. ${ }^{31}$

Una primera apreciación en la consideración de los derechos humanos en el campo del DIE es evitar caer en el equívoco de pensar que la relación con éstos se da en la esfera del derecho público; esto es en la relación entre instituciones de gobierno y personas. Por el contrario, el ámbito económico cuenta principalmente con un componente privado en el cual, las reglas del mercado son el principal motor; y por tanto es un error abstraer la aplicación de los derechos humanos exclusivamente al escenario gubernamental. Así, la rentabilidad en una economía de mercado es el factor determinante de sus operadores, con lo cual los elementos de bienestar social o individual son realmente periféricos en el proceso económico. ${ }^{32}$

Lo que parece ser un éxito de los principios de libre empresa sobre otras formas de ideología económica, ha supuesto una clara reticencia de los economistas a cualquier tipo de orientación social del mercado, lo cual ha trascendido al ámbito normativo internacional a través del DIE. Así pues, en el contexto global, si bien podemos encontrar una cierta regulación al comercio, las inversiones o el flujo de capitales, lo cierto es que en términos generales estamos ante un fenómeno de auto-regulación a través de figuras contractuales de índole comercial, en donde pareciera no haber espacio para contenidos propios de derechos humanos.

Como bien critica Philip Alston, el intento de exclusión de los derechos humanos del proceso de creación del DIE es del todo reduccionista,

31 Addo, Michael, "Human rights perspectives of International Economic Law", en varios autores, Perspectives..., cit.; Weiss, Friedl y Denters, Erik, International Economic Law with human face, La Haya, Kluwer, 1998.

32 Véase Friedman, Milton, "The social responsibility of business is to make profits", en Steiner, R. (ed.), Issues in Business and Society, Random House, Chicago, Chicago University Press, 1977; Friedman, Milton, Capitalism and Freedom, Chicago, Chicago University Press, 1962; Keynes, John, The collected writings..., cit.; Prebisch, Raúl, Introducción a Keynes..., cit.; Klein, Robert, The keynesian revolution..., cit.; Pigou, Arthur, Socialismo y capitalismo comparados..., cit. 
pues los asuntos económicos no existen en un mundo distinto al de las personas. ${ }^{33}$ Así, una de las primeras críticas que puede hacerse al proceso creativo del DIE a través de varias de sus organizaciones multilaterales - en el FMI, el Banco Mundial y la OMC - es la miopía con la que algunos contenidos normativos y de aplicación suelen tratarse, al no tomar en cuenta una dimensión realmente interdisciplinaria que incluye la acción de los derechos humanos, del ambiente, del género, etcétera.

El error conceptual de fondo - como apunta Addo- está en considerar a la persona humana como "lo otro", lo distinto, lo ajeno al DIE. ${ }^{34}$ Esta construcción es desde luego, artificial, ya que no toma en cuenta el rol central del ser humano en la economía, ya sea como consumidor o como trabajador, y es en cualquiera de esos dos caracteres que el DIE está obligado a incluir elementos de derechos humanos en sus normas y políticas públicas derivadas. Así, el derecho de la persona a ser reconocido en una dimensión humana integral no puede en modo alguno ser aislado de las decisiones normativas del DIE. Con ello, puede afirmarse que las disciplinas relativas a los derechos humanos y a la economía son un binomio mediante el cual debe dotarse a la sociedad de principios y normas justas de actuación.

A partir de esta aceptación del vínculo entre los derechos humanos y el DIE, es factible reconocer los campos más visibles de incidencia de aquellos en éste. Así, desde la perspectiva de trabajador, entre las manifestaciones más claras en el ejercicio de los derechos humanos a ser tomadas en cuenta en la formulación del DIE se encuentra: las formas contemporáneas de esclavitud; el régimen laboral en la maquila; el abuso en el trabajo de los menores; las condiciones inhumanas de trabajo; la discriminación de toda índole; el abuso en el trabajo por adelantos o préstamos patronales. Desde el ángulo de consumidor, el ser humano está expuesto, entre otras muchas conductas a: la falta de información relevante sobre los productos y servicios que consume; el desarrollo de productos orgánicos e inorgánicos que ponen en riesgo la salud; la falta de acceso a mecanismos legales ágiles para ser indemnizados por la responsabilidad civil de productos defectuosos, etcétera. ${ }^{35}$

33 Alston, Philip, Commodity Agreements as though People don't Matter, JWTL (1981) 18.

34 Addo, Michael, op. cit., p. 147.

35 Véase Enríquez, David, Responsabilidad civil por productos defectuosos, México, Porrúa, 2003; Vega, Fernando de la, Responsabilidad civil derivada del producto defectuoso, Madrid, Civitas, 1988; Messina, Graciela, La responsabilidad civil en la era de la tecnología, Buenos Aires, 
Ahora bien, entre los valores que tanto la disciplina de los derechos humanos como el DIE comparten sin duda se encuentra el de la libertad. Nada obsta para negar la relevancia mayúscula de la libertad en el terreno del mercado, sin embargo el verdadero significado de la libertad en la economía se compone también de factores sociales y políticos en donde se reconoce la necesaria vigencia de los derechos humanos; y no solamente como un principio fundamental en los intercambios económicos. En efecto, el DIE tiene el deber ético de imponer límites a la libertad de mercado en función del respeto a la persona humana.

La consideración de la libertad económica no como un fin en sí mismo, sino como un medio que junto con otros instrumentes potencie la felicidad de las personas, la dignidad humana, la justicia y la equidad entre otros valores, ha sido afortunadamente incorporada incluso en los preámbulos declarativos de la constitución de algunos de los organismos internacionales más criticados en la instrumentación del DIE: la OMC. De este modo, si en el espíritu mismo de la creación de las principales instituciones del DIE se reconoce la preeminencia de los derechos humanos, resulta incongruente que las normas de naturaleza programática y taxativa con las cuales se concreta los acuerdos económicos a nivel multilateral no siempre respeten los principios que dan vida a sus instituciones. ${ }^{36}$

Desde una posición formal, no puede perderse de vista además que los Estados miembro de los principales organismos que crean e implementan el DIE, lo son también de una amplia gama de tratados internacionales en materia de derechos humanos. De modo que la separación artificial entre DIE resulta, tanto desde un análisis teleológico como desde una apreciación formal, infundada. ${ }^{37}$ En efecto, las normas de DIE que por su contenido directo o por los alcances de implementación se opongan a los tratados en materia de derechos humanos, harían que los países

Abeledo-Perrot, 1989. Véase asimismo los informes anuales de la Organización Internacional del Trabajo en materia de derechos humanos y condiciones laborales en www.ilo.org

36 Véase los acuerdos conclusivos de la Ronda de Uruguay de Negociaciones Comerciales firmados en Marrakech el 15 de abril de 1994, por el que se constituye la OMC. Véase lo relativo a las declaraciones en la constitución de la OMC en www.wto.org

37 Véase, por ejemplo, la Declaración Universal de los Derechos Humanos de 1948, el Pacto Internacional de Derechos Económicos, Sociales y Culturales de 1966 y el Pacto Internacional de Derechos Civiles y Políticos y su Protocolo Facultativo de 1976, entre otros varios de dimensión universal y regional. 
que las aplicaran incurriesen en responsabilidad, de acuerdo al derecho internacional público. ${ }^{38}$

La jerarquía en el respeto a los derechos humanos y a la necesidad de que los valores de éstos nutran las normas internacionales específicas, incluidas aquellas propias de los instrumentos del DIE, no solamente pueden localizarse en tratados propios de aquella materia, sino en la misma Carta de las Naciones Unidas, que es considerada el epicentro de la regulación internacional en materia de derechos humanos, pero también el eje de inspiración básica en el diseño y aplicación del DIE.

Así, los pueblos de las Naciones Unidas en la constitución misma de la organización reafirmaron la fe en los derechos fundamentales del hombre, en la dignidad y el valor de la persona humana, en la igualdad de derechos de hombres y mujeres y de las naciones grandes y pequeñas. Más aún, como propósito y principio común acordaron realizar la cooperación internacional para la solución de problemas internacionales de carácter económico, social, cultural o humanitario, y en el desarrollo y estímulo del respeto a los derechos humanos y a las libertades fundamentales de todos. ${ }^{39}$

En este contexto, la carta va más allá de los citados propósitos y ordena que los distintos organismos especializados establecidos por acuerdos intergubernamentales, que tengan amplias atribuciones internacionales relativas a materias de carácter económico, social, cultural, educativo, sanitario y otras conexas, deben ser vinculados con la ONU por medio de los acuerdos que concrete el Consejo Económico y Social — con aprobación de la Asamblea General-y los órganos de gobierno respectivos del organismo especializado que se trate. ${ }^{40}$

A reserva de algunas excepciones como la poderosa $\mathrm{OMC}$, muchos de los organismos internacionales creadores y operadores de normas de DIE - como el propio FMI y el Banco Mundial - han celebrado convenios con la ONU en sus respectivos ámbitos de validez. Así pues, podemos concluir que existen bases sólidas para reconocer la preeminencia estricta de los derechos humanos — según se dispone en la Carta de las Naciones Unidas - sobre toda negociación económica de los organismos especializados del sistema.

\footnotetext{
38 Véase, principalmente, la Convención de Viena sobre el Derecho de los Tratados de 1969, art. 26 y ss. Véase Seara, Modesto, op. cit., pp. 347 y ss.

39 Carta de las Naciones Unidas de 1945, proemio declarativo y art. 1.3.

$40 \quad$ Ibidem, arts. 57 y 63.
} 
Ahora bien, para aquellas organizaciones no vinculadas formalmente a dicho sistema - como la $\mathrm{OMC}$ - , existe tanto una clara orientación y costumbre de derecho internacional, como - ya hemos destacadocomo una obligación indirecta de atender los derechos humanos, toda vez que sus Estados miembro son signatarios de la Carta de la ONU y de una serie de instrumentos internacionales en materia de promoción y respeto a esta categoría de derechos; con lo cual, los gobiernos no pueden desconocer sus diversas obligaciones internacionales. DIE y derechos humanos pues, están y deberán siempre permanecer esencialmente unidos.

Pasemos ahora a un tópico mucho más debatido en las tendencias actuales sobre DIE: ¿cuál debe ser el tratamiento jurídico sobre el respeto a los derechos humanos en la esfera económica privada? De los anteriores párrafos, se ha tratado de salvar toda duda sobre el deber de los Estados en la materia a través de las normas de DIE. Sin embargo, la cuestión ahora es determinar si las relaciones económicas internacionales entre particulares derivadas del DIE, pero no sujetas a normas imperativas deben tener algún tratamiento jurídico en el campo de los derechos humanos.

Desde luego, no se pone en duda el rol del Estado y sus órganos de gobierno en vigilar la aplicación efectiva de la legislación nacional e internacional sobre el particular, se pretende más bien reconocer que entidades privadas - asociaciones, cámaras y sobre todo empresas de todo tamaño - representan en la práctica un papel que, sabiéndolo o no, repercute en la vigencia de los derechos humanos. Incluso, por su cercanía con la esfera natural de acción de la persona, son precisamente estas entidades las que pueden tener una mayor influencia eficaz en su promoción. ${ }^{41}$

En este contexto, no es exagerado señalar que varias de las empresas multinacionales más grandes del mundo cuentan con personal y presupuesto más extenso que el de muchos países. ${ }^{42}$ Además, a través de sus políticas empresariales y códigos de conducta ejercen una supervisión es-

41 Véase Weiss, Friedl, International Economic Law with a Human Face, La Haya, Kluwer, 1998; Meyer, William, Human rights and international political economy in third world countries, Westport, 1998; Bronckers, Marco y Quick, Reinhard (ed.), New Directions in International Economic Law, La Haya, Kluwer Law International, 2000.

42 La magnitud de las 500 empresas más grandes del mundo puede analizarse a través de Fortune500.com en el cual se actualizan los principales indicadores corporativos con periodicidad. 
trecha respecto a algunas de las libertades fundamentales de la persona, así como sobre su estilo de vida. ${ }^{43}$ Pero no sólo existe un punto de conexión entre las multinacionales y sus empleados que interesa al terreno de los derechos humanos, sino uno sin duda más extenso: el de su incidencia en la calidad de vida de los consumidores a través de la adquisición de sus productos y servicios.

Así por ejemplo, la disponibilidad, calidad y cantidad de medicamentos y alimentos, entre otros recursos a escala mundial, sin duda afecta la calidad de vida de millones de personas, y con ello la vigencia efectiva de sus derechos humanos. El grado de afectación que las grandes empresas pueden generar — para bien o para mal— puede estudiarse con precisión en las actividades económicas de países en desarrollo originalmente operadas a través de empresas paraestatales que más tarde han sido privatizadas. Así, bienes y servicios públicos son controlados y administrados por entidades privadas que naturalmente gozan de un poder sustancial en sus respectivos mercados relevantes, de modo tal que el límite entre el contenido social de los servicios ofrecidos y la libertad económica de estas empresas es cada vez más sensible.

Como acertadamente explica Michael Addo, desde la perspectiva internacional de los derechos humanos, las relaciones privadas que afectan el terreno de los derechos humanos no pueden ser exentas del escrutinio público. ${ }^{44}$ Por ello, con base en los principios de subsidiaridad, efectividad y enfoque en el sujeto pasivo de la violación, la interpretación contemporánea de los instrumentos internacionales en la materia favorece la aplicación estricta sin importar la fuente de la violación; es decir impone de modo indirecto obligaciones de derechos humanos también a sujetos de derecho privado, como son las empresas multinacionales. ${ }^{45}$

Es de esta forma que los Estados contratantes adquieren una obligación general de respeto y promoción de los derechos humanos hacia todos los gobernados dentro de su jurisdicción, con la importante connotación consistente en que esta obligación se extiende al deber de supervisión del Estado en el campo de las relaciones privadas. Con lo cual, la

43 Véase Carrasco, E. y Singh, T., The content and focus of the Codes of Ethics of the World's Largest Transnational Corporations, N. Y., Blackwell Publishing, 2003.

44 Addo, Michael, op. cit., p. 150.

45 Véase en este sentido la aplicación el Convenio Internacional sobre Derechos Civiles y Políticos (1966) art. 2.1; o de la Convención Americana sobre Derechos Humanos (1969) art. 1. 
falta de supervisión adecuada de este tipo de relaciones acarrea la responsabilidad internacional del Estado mismo. ${ }^{46}$

Entre los deberes consecuentes de supervisión de la vigencia de los derechos humanos por parte de los Estados —incluso al ámbito privado- se encuentra la necesidad de promulgar la legislación y reglamentación que se requiera; la constitución y operación efectiva de instituciones protectoras de los derechos humanos; la creación de cuerpos policíacos capaces de contrarrestar las violaciones; la composición de tribunales autónomos; los mecanismos institucionales eficaces para supervisar el respeto a los derechos humanos en el ámbito privado, etcétera.

Este tejido normativo en el campo de los derechos humanos permite afirmar que las normas de DIE incorporadas y aplicadas por un Estado directa o indirectamente - a través de la libertad económica a ejercer de modo privado por empresas e individuos - que contradigan los instrumentos internacionales en la materia que ahora tratamos, acarrea la responsabilidad del Estado que debía ejercer la supervisión y que fue omiso o negligente en ello. Estos casos son justiciables contra los Estados infractores, tanto en tribunales nacionales como en foros supranacionales con jurisdicción en la materia, como la Corte Interamericana de Derechos Humanos.

$\mathrm{Al}$ respecto, los tratados internacionales aplicables permiten no solamente imponer obligaciones programáticas a los Estados para que no se repita la violación, sino sanciones económicas que tienen en cuenta los daños y perjuicios, así como la afectación al proyecto de vida de las víctimas. ${ }^{47}$ Entre los principios que más claramente se siguen por parte de los tribunales internacionales hoy en día, está el de centrarse en la posición de la víctima, con lo cual de escasa trascendencia será intentar el argumento defensivo consistente en señalar la naturaleza privada de la relación que dio origen a la violación de los derechos humanos del caso específico.

La confrontación entre DIE y derechos humanos se hace patente en algunas normas de índole comercial negociadas en el ámbito de la OMC. Así, lejos de ser ocioso argumentar a favor del estrecho vínculo entre

46 En el ámbito regional, uno de los casos más importantes en materia de supervisión estatal sobre la vigencia de los derechos humanos en el terreno privado fue el resuelto por la Corte Interamericana en Velásquez Rodríguez v. Honduras, Serie C, núm. 4, 1988.

47 Véase Calderón, Jorge, El daño al proyecto de vida por violaciones a los derechos humanos, México, Porrúa, 2004, Breviarios Jurídicos. 
DIE y derechos humanos, resulta de la mayor trascendencia, con lo cual debe quedar advertido a los Estados y a los sujetos de derecho privado: existen fuentes vinculantes para constatar que se realiza una efectiva promoción, respeto y supervisión de los derechos humanos tanto en la relación Estado-gobernado, como en la esfera de las relaciones privadas.

\section{B. Consideraciones de género}

Para Graciela Hierro, la categoría central aplicable a la condición femenina es la de "ser para otro". Esta categoría fue inicialmente acuñada durante las primeras décadas del siglo XX por Simone de Beauvoir, una de las feministas de mayor trascendencia en la historia de los movimientos sociales. Así, en opinión de Hierro, ese "ser para otro" se concreta en la mujer a través de su situación de interiorización, control y uso; que no son más que los atributos derivados de su condición de opresión como ser humano, a quien no se le concede la posibilidad de realizar un proyecto de trascendencia. ${ }^{48}$

Como explica Ana Echeverri, fue a partir del planteamiento de Beauvoir relativo al género como categoría social impuesta sobre un cuerpo con ciertas características sexuales — bien sea femenino o masculinoel feminismo, tanto como movimiento político como teoría filosófica, se ha orientado hacia dos corrientes que parecen lógicamente incompatibles. Así, encontramos por un lado, la que rechaza la inferioridad natural de lo femenino; y por el otro, la que define la propia feminidad según características deducidas del supuesto de inferioridad natural. ${ }^{49}$

Feminismo de la igualdad y feminismo de la diferencia son pues, los dos movimientos sociales a partir de las cuales se ha construido un marco teórico amplio en materia de género, con consecuencias prácticas tanto en el terreno legislativo como en el diseño y aplicación de políticas sociales. Mientras que la primera corriente encuentra sustento filosófico en la ética de la Ilustración; la segunda surge en un contexto de movimientos críticos al pensamiento ilustrado de la Modernidad.

Con el fin de estar en una mejor posibilidad de analizar la dinámica del derecho internacional, y especialmente del DIE, en torno a los estudios de género, comentaremos brevemente algunos de los contenidos

48 Hierro, Graciela, Etica y feminismo, México, UNAM, 2003, p. 17.

49 Echeverri, Ana, "Comentario a Dora Sierra", La discriminación contra la mujer en el derecho mexicano, México, Porrúa, 2004, p. X. 
más relevantes de ambas corrientes sociales feministas. La todavía escasa literatura jurídica relativa a género y a los cuestionamientos válidos de esta disciplina sobre las normas del DIE, nos parece que amerita estas líneas.

Como afirma Estela Serret, la precondición del feminismo - en el ámbito de la Ilustración - es el planteamiento ético que cuestiona las desigualdades "naturales" entre los seres humanos y funda la legitimidad del orden político. ${ }^{50}$ Gracias a este supuesto ilustrado es que pudo edificarse el reclamo propiamente feminista por el reconocimiento de las mujeres como ciudadanas y sujetos autónomos. A pesar de sus orígenes en el pensamiento ilustrado, el feminismo advirtió serias contradicciones en su discurso filosófico y político.

Así, la Ilustración por una parte abanderaba la causa de la emancipación humana a través del reconocimiento de la igualdad natural entre todas las personas; pero por otra, consideraba que las mujeres debían seguir subordinadas a los hombres, a causa de su supuesta inferioridad natural. En la Ilustración, el feminismo de la igualdad encontró las dos caras de una misma moneda: el postulado positivo de la igualdad natural de los seres humanos —en tanto racionales - así como la incongruente valoración negativa de la irracionalidad de las mujeres, lo cual impedía otorgarles reconocimiento y derechos como iguales. Así, la supuesta irracionalidad femenina derivó en su exclusión de toda consideración científica o política. Por tanto, aparentemente se perdió la oportunidad para las mujeres de trascender del ámbito privado — como auténtico sujeto autónomo - para permanecer en la milenaria invisibilidad de la sociedad patriarcal.

La oposición que a partir de la segunda mitad del siglo XVIII manifestó el Romanticismo, en contra de la Ilustración por el aludido carácter deshumanizante y el egoísmo de sus cálculos racionales, no aportó beneficios significativos al debate feminista. Por el contrario, en un afán am-

50 Serret, Estela, Identidad femenina y proyecto ético, UAM, PUEG, 2002, pp. 12 y ss. Sin embargo, valga advertir — siguiendo a la autora - que en sus disquisiciones sobre la igualdad natural, los exponentes del pensamiento ilustrado (Poulain de la Barre, Von Hippel, Taylor, Condorcet, D’Alembert, Diderot, etcétera), ni siquiera se preguntaron si sería pertinente considerar que la mujer podía ser un sujeto moral autónomo y por tanto susceptible de ser tratado como un igual. Este, era un privilegio del hombre, blanco, cristiano, jefe de familia y civilizado. Situación que no solamente las mujeres, sino todos los demás grupos - ya fuera por condición económica, raza o religión- no compartían. Así, el tratamiento de igualdad y por tanto el reconocimiento para participar en las ciencias, artes o política estaba reservado para el hombre que gozara de dichos privilegios. 
biguo por mistificar los valores considerados como femeninos, pareció dar un paso más en la cultura de la misoginia, ya que sin mayores razonamientos desconoció una vez más la posibilidad de valorar a las mujeres como sujetos racionales con un rol activo en la sociedad.

No sin acabar con las contradicciones propias del pensamiento ilustrado que antes advertíamos, el feminismo de la igualdad se propuso llevar al terreno de la legislación internacional la estrategia de la igualdad; una estrategia que no admitía la diferencia ni la multiplicidad entre géneros. Fue en este contexto ideológico como en 1979 fue suscrito un instrumento internacional en materia de género, de vocación prácticamente universal: la convención para la eliminación de toda forma de discriminación contra las mujeres (CEDAW, por sus siglas en inglés).

Si bien CEDAW representa el logro multilateral más grande en el reconocimiento integral de la mujer en la vida pública; y por tanto un éxito de conjunto para los distintos movimientos feministas y de la teoría de género como recipiente institucional de dichas corrientes, lo cierto es que en este cuarto de siglo y tras cuatro conferencias internacionales sobre las mujeres desde su creación, parece claro que sus problemas de implementación efectiva derivan de un equívoco intrínseco, al haberse negado a reconocer que mujeres y hombres somos distintos.

El problema - de raíces conceptuales y consecuencias de regulación prácticas - estriba en dar un paso decisivo para precisar la identidad femenina y la masculina, con el fin de ofrecer criterios que mejoren la calidad de vida y la participación pública de las mujeres, a partir del carácter y las necesidades diferenciadas en cada género. Es en este sentido, como los estudios interdisciplinarios en materia de género, buscan hacerse eco dentro de las revisiones a la estructura y contenido de los tratados internacionales, incluido CEDAW.

Desde la perspectiva del DIE, uno de los instrumentos de mayor relieve en los compromisos multilaterales sobre género es la Declaración de Beijing y la Plataforma de Acción de Beijing; ambos derivados de la Cuarta Conferencia Mundial sobre las Mujeres, llevada a cabo en septiembre de $1995 .{ }^{51}$ A los diez años de haber sido adoptada, la Plataforma

51 Junto con CEDAW y las otras cuatro conferencias internacionales sobre mujeres llevadas a cabo en la historia de la ONU, la Plataforma de Acción de Beijing, puede ser vista como un siguiente paso a las Estrategias de Avance de las Mujeres, adoptadas en Nairobi en 1985. En general, el capítulo II de la plataforma esboza los instrumentos internacionales que le sirven como contexto. 
de Acción de Beijing fue revisada en una conferencia multilateral similar en febrero de 2005 en Nueva York. El instrumento es conocido como Beijing Más Diez, pues ha sido sujeto a análisis de cumplimiento, luego de una década de asumidas las obligaciones por países y organismos internacionales.

La plataforma de acción es en realidad una agenda para el empoderamiento de las mujeres. Busca acelerar la implementación de una serie de estrategias multilaterales para el avance de la mujer; así como remover los obstáculos existentes para la participación activa de la mujer, tanto en el ámbito público como en el privado; esto mediante la toma de decisiones equitativa en las dimensiones económica, social, cultural y política de la vida. La plataforma entiende la equidad entre mujeres y hombres como una cuestión de derechos humanos; así como una condición para la justicia social, el desarrollo sustentable y la paz.

La Plataforma de Acción de Beijing destaca una docena de áreas de especial preocupación para la equidad de género. Entre éstas: la persistente y creciente carga de la pobreza sobre las mujeres; acceso no equitativo e inadecuado a la educación, la capacitación y la salud; violencia contra las mujeres; los efectos de conflictos armados sobre las mujeres; falta de equidad en la estructura y la política económica; falta de equidad en el acceso al poder y la toma de decisiones políticas; mecanismos insuficientes para la promoción del avance de la mujer; falta de respeto y de promoción adecuadas para la protección de los derechos humanos de las mujeres; falta de equidad en el acceso a medios de comunicación y continuación de estereotipos femeninos; inequidad en el manejo de recursos naturales y protección al ambiente; y discriminación persistente y violación de los derechos humanos de las niñas.

A diferencia de los Objetivos del Milenio que hemos ya comentado brevemente, la plataforma de acción contiene una serie de acciones programáticas muy específicas, ordenadas a partir de estrategias dirigidas principalmente tanto a organismos internacionales como a gobiernos nacionales; pero también a organismos intermedios y a la sociedad civil en general. Los grupos de estrategias abarcan combate a la pobreza; educación y capacitación; salud; economía; medios de comunicación; y ambiente.

El avance de los movimientos sociales feministas ha servido pues, para construir instrumentos internacionales sobre género, como los que hemos expuesto. Ahora bien, la variedad de estos movimientos sociales 
provoca, sin embargo, que una posición única sea auténticamente quimérica para establecer políticas efectivas de género. Un ejemplo de esta riqueza - o tal vez dispersión - de debate es el de algunas feministas posmodernas. Como advierte Serret, este grupo, siguiendo en gran medida las propuestas post-estructuralistas pretende eliminar las esencias en la discusión sobre la feminidad, ofreciendo con ello un discurso que curiosamente busca además ser un no-discurso. ${ }^{52} \mathrm{~A}$ pesar de las críticas presentadas por Serret y otras autoras, nos parece que no debe perderse de vista que es gracias a una perspectiva posmoderna de género que se han puesto de manifiesto las marcadas diferencias entre las mujeres, derivadas de su raza, cultura, religión, edad, etcétera.

Ante este caudal teórico, parece que el pragmatismo debería tener una palabra: con independencia de sus diferencias ideológicas, el objetivo común práctico de los movimientos feministas, debería centrarse en la elevación de la calidad de vida, así como en la facilitación de la felicidad de las mujeres, en un entorno de respeto integral entre unas y otros. Entre las alternativas, que a nuestro parecer, resultan más acertadas para conseguir este objetivo, se encuentra la aproximación de género a los planes y políticas de desarrollo; mejor aún, la aproximación de los derechos humanos de las mujeres en todas las cuestiones de desarrollo. Mediante ellas, se busca diferenciar de modo efectivo las necesidades de los muy variados grupos de mujeres; tomando en cuenta factores clave: edad, cultura, religión, nivel educativo, condiciones socioeconómicas y sanitarias, nivel de empoderamiento en la familia y la sociedad, etcétera. Veamos en qué medida el DIE ofrece respuestas a esta urgencia social.

La interacción jurídica entre género y economía a un nivel internacional, se da fundamentalmente en el ámbito de los derechos humanos de las mujeres; y es a partir de esa interacción que puede entenderse su incursión en el ámbito del DIE. En este contexto y como acertadamente señala Rebecca Cook, la disciplina de los derechos humanos de las mujeres no ha sido todavía implementada de manera eficaz como para revertir las desventajas e injusticias que éstas experimentan por el solo hecho de ser

52 Ibidem, p. 21. Véase Squires, Judith, Gender in political theory, Cambridge, Polity Press, 1999, pp. 16 y ss.; Mackkinnon, Catherine, Hacia una teoría feminista del Estado, trad. de Eugenia Martín, Universidad de Valencia, 1989, pp. 391 y ss. 
lo que son. Por supuesto, las razones de esta falla generalizada del sistema de derechos humanos es compleja, y varía de país en país. ${ }^{53}$

Entre las causas sin duda, se encuentran la falta de comprensión de la naturaleza perenne de subordinación de las mujeres; el fracaso en reconocer la necesidad de caracterizar tal subordinación, como una violación de derechos humanos; y la falta de una práctica real por parte del Estado, en la condena a la discriminación de las mujeres. Más aún, se ha llegado incluso a la aberración de que grupos de promoción de derechos humanos se han mostrado reacios a centrar su actividad también a las violaciones de derechos humanos de las mujeres. Finalmente, una causa no menos importante, es que los propios grupos de feministas en algunos países no han comprendido el potencial del sistema como motor para reivindicar sus derechos.

Ahora bien, para estar en posibilidades de plantear una perspectiva de género sobre el DIE, parece necesario primer hacer una breve pausa en sus fuentes reales. Es decir, en la incidencia del proceso de globalización económica en el desarrollo - $\mathrm{O}$ no- de las condiciones de vida de las mujeres. En primer lugar, es necesario reconocer el avance de la llamada economía de género, a partir de la cual se han estructurado índices desagregados que toman en cuenta con cierto nivel de detalle indicadores de género y que aprovechan como referencia la experiencia en medición del Índice de Desarrollo Humano (HDI) ampliamente usado tanto en el Sistema de las Naciones Unidas como en otros foros.

Los dos principales índices desagregados en materia de género son el Índice de Desarrollo con relación a Género (GDI) basado en diferencias de género en cuanto a expectativa de vida, nivel de ingresos, grado de analfabetismo y deserción escolar. El segundo es la Medición de Empoderamiento de Género (GEM) y se basa en la proporción de mujeres en los congresos, en la administración pública, en la gerencia, así como la proporción de trabajadoras profesionales y técnicas.

Además del FMI y el Banco Mundial, entre los muchas entidades internacionales que hacen uso y sistematizan la información se encuentran el Programa de las Naciones Unidas para el Desarrollo (PNUD), y en especial el Fondo de Desarrollo de las Naciones Unidas para la Mujer (Unifem) y el Instituto Internacional de Investigación y Capacitación para la Promoción de la Mujer (Instraw). 
Si bien pueden hacerse críticas a estos dos tipos de mediciones -fundamentalmente en la insuficiencia del análisis cuantitativo para medir el desarrollo humano - lo cierto es que, al menos, permiten sacar a las mujeres de la invisibilidad estadística en la que siempre han estado y comparar la evolución entre países, y servir así de instrumentos para el DIE y para las políticas sociales que de él se desprenden. ${ }^{54}$

La economía de género como bien explica Lourdes Benería representa un reto a los métodos y tópicos de la economía tradicional, tanto en su contenido histórico, como en el análisis teórico y empírico de sus postulados. Entre los múltiples retos se encuentra la necesaria de-construcción de la economía ortodoxa particularmente en su acepción neoclásica para dotarla de una perspectiva feminista. Este esfuerzo, señala Diana Strassmann, ha incluido la crítica a las formas en las cuales se asume que el mercado y la sociedad civil dentro de éste, debe actuar. El debate así toma en consideración la naturaleza del mercado, sus objetivos, sus límites tanto respecto a seres humanos como respecto a comunidades, la validez de la eficiencia económica, etcétera. ${ }^{55}$

Otra prueba más del acelerado desarrollo de la economía de género - y la necesaria afectación que tarde o temprano tendrá en el DIE - es el cambio del objetivo del análisis económico del énfasis en la "opción" al "aprovisionamiento" para el bienestar individual y comunitario. Más aún, esta nueva especialidad de la economía ha puesto de manifiesto la predisposición individualista e incluso androcéntrica de ciertos modelos micro-económicos convencionales en teorías económicas sobre el consumo o el valor.

Uno de los avances de mayor relevancia de la economía de género para el desarrollo del DIE - particularmente en organizaciones internacionales como la OIT - es el relacionado con el trabajo remunerado de las mujeres y la equidad de oportunidades. Entre las varias áreas de investigación que se han abierto en este ámbito se encuentran las políticas de empleo y las políticas familiares con relación a la incorporación de las mujeres al mercado de trabajo remunerado.

La investigación realizada en este campo, tiene en cuenta horarios, diferencias de clase socioeconómica, raza, origen étnico y sexualidad; 
todo ello vinculado a la discriminación y a la segregación de las mujeres de la posibilidad de encontrar y mantener un trabajo pagado. Desde luego, el análisis del mercado laboral, no podría estar completo sin la incorporación de las consecuencias de la globalización en la dinámica del trabajo de un país a otro en cada sector de la economía, principalmente en los procesos fabriles y de maquila; así como el factor de migración como elemento adicional a la problemática del empleo y de su medición. ${ }^{56}$

Como ya antes hemos advertido, la vinculación entre género y economía en el ámbito del derecho internacional, se da fundamentalmente a través del respeto y la promoción de los derechos humanos de las mujeres. Al igual que lo dicho respecto a la perspectiva de derechos humanos en general, es conveniente tener en cuenta que la mayoría de los Estados que suscriben y ratifican instrumentos internacionales en materia de DIE son además uno de los más de ciento sesenta países que ha ratificado la CEDAW.

Así, aprobar normas de DIE y aplicar políticas públicas que deriven de éste y sean contrarias a los derechos humanos de las mujeres consagrados en CEDAW y otros tratados, significaría una violación del orden internacional y por tanto, una responsabilidad del Estado en la esfera del derecho internacional. Más aún, esta incongruencia de implementación legal por parte de un Estado legitimaría a toda mujer para demandar la responsabilidad del Estado tanto ante el foro nacional, como ante tribunales internacionales como la Corte Interamericana de Derechos Humanos, con el derecho consecuencia de reclamar daños y perjuicios ordinarios, así como en caso de demostrarlo, la reparación del daño por concepto de proyecto de vida. ${ }^{57}$

Si bien el campo del DIE en relación al feminismo, como señala Mary Childs, tiene todavía muy poco camino andado, lo cierto es que ha propiciado al menos un dinámica transversal de neutralidad de género tanto en el proceso creativo de la norma de DIE, como en la incorpora-

56 Véase Chant, Sylvia, Gender in Latin America; Latin America Bureau, Londres, 2003, p. 194.

57 Esta posibilidad no es un mero ejercicio académico, sino una realidad ya observada en el seno del Comisión de Derechos Humanos de la ONU en casos como SWM Broeks v. Países Bajos. UN Hum. Rts. Comm. 29th. Sess. (1987) con relación a un caso de discriminación laboral en materia de beneficios por desempleo reconocido por el gobierno holandés. 
ción de las mujeres en las estructuras de organismos internacionales del Sistema de la ONU y de fuera de éste. ${ }^{58}$

De nuevo, el foco de atención en la falta de consistencia entre los derechos humanos y el DIE se da en el ámbito de la OMC y el FMI-Banco Mundial, en aplicación de las normas de DIE que les aplican. Si bien, nos reservamos el análisis de estas dos instituciones y su actuación crítica en el campo del DIE y los derechos humanos, conviene adelantar que una de las mayores afectaciones a los derechos humanos de las mujeres deriva de la implementación de los programas de ajuste estructural impuestos por el Banco Mundial a una variedad de países en desarrollo. Estos programas han tenido como resultado recortes de presupuesto en áreas de atención médica y en ocasiones, en despidos masivos de trabajadoras. ${ }^{59}$

El rol normativo de la $\mathrm{OMC}$ no ha sido menos negativo para las mujeres. La liberalización del comercio y los servicios negociados al amparo de los instrumentos de DIE, en muchos casos han servido como incentivo a empresas multinacionales para instalar empresas — principalmente maquiladoras de textiles y otros productos - en países de gran oferta de mano de obra femenina y de consecuente bajo costo laboral.

En esos países, la escasa regulación de trabajo y de seguridad social conlleva la explotación intensiva de mujeres —además de niñas y niños-, quienes estadísticamente tienen un mejor desempeño profesional, ocasionan menos "problemas" a la empresa y pueden ser despedidas con mayor facilidad ante el "riesgo" de tener que pagarles beneficios de seguridad social fundamentales, como periodos de incapacidad laboral por maternidad, jornadas especiales por lactancia o guarderías. ${ }^{60} \mathrm{La}$ ironía está en que en el mundo desarrollado - incluido el de las feministas consumidoras - los productos elaborados por las manos de mujeres explotadas laboralmente, reúnen las condiciones necesarias de calidad y precio para el mercado, que permiten alimentar la cadena de injusticia e inequidad global en que vivimos.

\footnotetext{
58 Childs, Mary, "Femenist Perspective on International Economic Law", en varios autores, Perspectives..., cit., p. 163.

59 Véase Chant, Sylvia, op. cit., pp. 98 y ss.

60 Idem. Véase igualmente Beneria, Lourdes, op. cit., pp. 63 y ss.
} 


\section{Perspectivas de desarrollo sustentable}

\section{A. Ambiente y desarrollo sustentable: los primeros pasos}

La acuñación conceptual y la evolución normativa del desarrollo sustentable no fue considerado con entidad propia por la comunidad internacional, sino hasta inicios de la década de los ochenta, en que se creó la primera Estrategia Mundial para la Conservación. ${ }^{61}$ Esta preocupación - tardía - en el tema tomó nuevo impulso al final de esa década a través del reporte Nuestro Futuro Común de la Comisión Mundial sobre Ambiente y Desarrollo en 1987, entidad creada por la Asamblea de la ONU en $1983 .{ }^{62}$ Desde entonces, la agenda internacional de la ONU y sus organismos especializados ha tenido una fuerte inclinación por la perspectiva del desarrollo sustentable. La efectividad de esta preocupación, si bien ha tenido algunos avances, está todavía por verse.

La comisión -independiente de gobiernos nacionales y de la propia ONU - actuó a partir de una instrucción clara de dividida en tres tareas: re-examinar los asuntos críticos relativos al ambiente y al desarrollo para con ello formular propuestas realistas; proponer nuevas formas de cooperación internacional con la dirección adecuada en los temas que deban influenciar políticas públicas; hacer lo necesaria para elevar el nivel de entendimiento y compromiso hacia acciones específicas por todos los sectores de la sociedad y los gobiernos.

Con el propósito de dar el suficiente rigor y objetividad a su reporte, la comisión valoró una serie de documentos de carácter científico y recogió testimonios de muy diversas instituciones y personas en los cinco continentes. De todo ese trabajo, los propios comisionados concluyeron lo que ya parecía evidente aún en esa fase de la globalización económica. Las tendencias de desarrollo de la época dejaban un número cada vez

61 Pinto, M., "The legal context: concepts, principles, standards and institutions", en Weiss, Friedl, op. cit. Valga señalar que un antecedente más de importancia en el sistema multilateral en material de desarrollo sustentable es la Declaración de las Naciones Unidas derivada de la Conferencia sobre Ambiente Humano de 1972 celebrada en Estocolmo, Suecia. Su relevancia está en la formulación de una serie de principios sobre conservación. Desde luego, existe además una serie de resoluciones de la Asamblea General de la ONU que con antelación han tenido impacto en la evolución del desarrollo sustentable. Una de ellas, es la Resolución 1831 sobre Desarrollo Económico y Conservación de la Naturaleza de 1962.

62 La comisión fue creada en parte por el momento político idóneo generado a partir de la llamada Carta Mundial para la Naturaleza de 1982, de acuerdo a una resolución de la Asamblea General de la ONU (Res. 37/7). 
más alto de personas pobres y vulnerables; y al mismo tiempo omitían tomar en cuenta el factor ambiental.

La pregunta de los comisionados a la comunidad internacional resultaba también evidente: ¿Qué tanto podrían servir estas tendencias de desarrollo durante el siglo XXI en el cual, el doble de la población tendrá que vivir en el mismo ambiente? Con suficiente comprensión y compromiso sobre el problema por parte de todos los países - con independencia de su nivel de avance económico—63 la comisión instó a generar un nuevo patrón de desarrollo. Uno que sustente el progreso humano no solo en algunos lugares y por algunos años; sino para todo el planeta hasta el futuro distante. Con estas palabras, el término desarrollo sustentable quedó inscrito con carácter permanente en la agenda multilateral.

Unos años más tarde - en 1992- la Conferencia de las Naciones Unidas sobre Ambiente y Desarrollo adoptaba en el marco de la Cumbre para la Tierra la Declaración de Río, con lo cual por primera vez de un modo integral se fijan los límites al DIE. En efecto, si los gobiernos nacionales y los organismos internacionales pretenden ser congruentes con lo que acuerdan en uno y otro foro, las normas de DIE deben estar alimentadas por consideraciones de desarrollo sustentable, y quien las aplique en la práctica gubernamental local, está obligado a dar una lectura integrada y coherente de un entramado de fuentes internacionales entre las cuales, el desarrollo sustentable debe tener su lugar. ${ }^{64}$

En términos generales, la Declaración de Río estableció los principios y lineamientos del patrón de desarrollo por los cuales se preguntaba la Comisión años atrás: los proyectos de desarrollo económico deben involucrar acciones específicas de protección ambiental eficaz y permanente, basada en una red de tratados de naturaleza absoluta o relativamente ambiental. Como veremos líneas abajo, a partir de la Declaración de Río se ha intentado articular un sistema articulado de acciones a favor del desarrollo sustentable que favorezca la aplicación efectiva de la legislación

63 Es de llamar la atención que durante el impulso que en los setenta intentaron dar los países - entonces llamados - tercermundistas, al multilateralismo, el tema del desarrollo sustentable no tuvo un verdadero reconocimiento. Así, no aparece de modo expreso y contundente ni en las resoluciones de la Asamblea General de la ONU sobre el llamado nuevo orden económico internacional (Res. 3201 y 3202) ni la Carta de Derechos Económicos de los Estados (Res. 3281).

64 El paquete de lo negociado en la Cumbre de Río integra la declaración, el convenio sobre biodiversidad y la declaración no vinculante relativa a los principios para un consenso general en materia de manejo, conservación y desarrollo sustentable para todos los tipos de bosques. 
ambiental, sin deterioro del crecimiento económico; todo ello a través del plan de acción conocido como Programa 21.

El Programa 21, enriquecido más tarde por su revisión en la Cumbre de Johannesburgo de 2002 representa sin duda la agenda más detallada de la historia multilateral en cuestiones de desarrollo sustentable. Está dividido en cuatro grandes secciones: dimensiones sociales y económicas; conservación y manejo de recursos para el desarrollo; fortalecimiento de la participación; y formas de implementación. Si bien las medidas no gozan de naturaleza vinculante y sancionable, sí significan el paso más importante en el reconocimiento de que la única forma de acceder a una globalización económica justa y equitativa es a través de la efectividad del desarrollo sustentable. ${ }^{65}$

En nuestra opinión, un acierto de la Cumbre de Río fue sensibilizar a los gobiernos en la necesidad de articular un sistema coherente de aplicación de tratados internacionales en materia ambiental; y considerar este objetivo como una condición fundamental para el desarrollo sustentable. Para ello, en una compleja red de fuentes del derecho ambiental, conviene recordar algunos de los tratados más importantes que inciden en el desarrollo sustentable: el Convenio sobre Diversidad Biológica de 1992, la Convención Marco de las Naciones Unidas sobre el Cambio Climático de 1992, la Convención de las Naciones Unidas sobre el Derecho del Mar de 1982, el Convenio Internacional para Prevenir la Contaminación por los Buques de 1973, el Convenio sobre el Tráfico Internacional de Especies en Peligro de Extinción de 1973, la Convención sobre la Conservación de Especies Migratorias de Animales Silvestres de 1979, el Acuerdo Internacional para la Conservación y Ordenación de las Poblaciones de Peces Transzonales y las Poblaciones de Peces Altamente Migratorias de 1995, y el Acuerdo Internacional de las Maderas Tropicales de 1994, entre otros muchos más instrumentos especiales y regionales. ${ }^{66}$

En la opinión de algunos especialistas, la legislación ambiental internacional en su estado actual, luego de un importante salto en la década de los noventa, parece regular suficientemente el uso y explotación de recursos naturales de un modo sustentable. De acuerdo con A. Boyle, el

65 Véase www.un.org/esa/sustdev/documents/agenda21

66 Véase los aspectos ambientales relacionados con el desarrollo sustentable en Sands, Philippe, Principles of International Environmental Law, Cambridge, Cambridge University Press, 2003; Kubasek, Nancy; Environmental Law, Nueva Jersey, Prentice-Hall, 2000; Hunter, David et al., International Environmental Law and Policy, N. Y., Foundation Press, 1998. 
mundo ha dado un giro de la mera explotación de recursos naturales para la obtención de ganancias comerciales y desarrollo económico al requerimiento obligatorio de la conservación y la explotación sustentable de recursos naturales. ${ }^{67} \mathrm{Si}$ bien las fuentes internacionales del derecho ambiental parecen haber tenido una importante evolución de modo relativamente reciente, la efectiva aplicación de éstas en un auténtico sentido de desarrollo sustentable, no es todavía una realidad. No resulta extraña la crítica consistente en que la creación de normas sobre desarrollo sustentable es todavía demasiado declarativa, vaga y general; en la dificultad de su implementación efectiva; así como en la falta de un sistema eficaz de sanciones económicas por su incumplimiento.

Estas y otras críticas han parecido relegar a la regulación del desarrollo sustentable — como a otras muchas disciplinas de índole social según hemos visto - al cajón categórico del llamado soft law. Esto es, a un conjunto de normas imperfectas que además, suelen considerarse de escasa o nula aplicación efectiva en las jurisdicciones nacionales. ${ }^{68}$

Una vez comentada la inserción del desarrollo sustentable en la agenda internacional, sus vínculos estrechos con las fuentes de derecho ambiental y sus críticas por la escasa operatividad real, observaremos ahora la evolución normativa e institucional que en el ámbito del DIE ha tenido el desarrollo sustentable dentro del sistema de las Naciones Unidas, particularmente a través de la Cumbre Mundial sobre Desarrollo Sustentable celebrada en Johannesburgo en 2002, diez años después de la Cumbre para la Tierra de 1992 de Río de Janeiro.

\section{B. Financiamiento y desarrollo sustentable: un segundo peldaño}

Si bien la Declaración de Río en la Cumbre de la Tierra de 1992 generó importantes tratados internacionales en materia ambiental, lo cierto es que los indicadores de desarrollo sustentable a los diez años de Río no

67 Boyle, A. y Freestone, D., International Law and Sustainable Development, Oxford, OUP, 1999 , p. 6.

68 Véase Subedi, Surya, "Sustainable development perspectives in International Economic Law", en varios autores, Perspectives..., cit.; Nollkaemper, Andre, "Rethinking states'rights to promote extra-territorial environmental values", en varios autores, International Economic Law with Human Face..., cit.; Douma, Wybe, Evolution and impact of sustainable development in the European Union, cit.; Peters, Paul, Sustainable development with a human face?..., cit.; Subedi, Surya, Foreign investment and sustainable development..., cit.; Loibl, Gerhard, The World Bank Group and sustainable development..., cit.; Denters, Erik, Financing the protection of global environment..., cit. 
fueron, ni por mucho, positivos. Para mejor entender los contenidos de la Cumbre de Johannesburgo debemos tener en cuenta dos instrumentos internacionales de DIE intermedios: los Objetivos del Milenio establecidos con precisión por la Asamblea General de la ONU en el 2000 y la Conferencia Internacional sobre Financiación para el Desarrollo llevada a cabo Monterrey en el 2002, que a continuación comentamos. ${ }^{69}$

En el documento más importante generado por la conferencia celebrada en nuestro país, el llamado Consenso de Monterrey se establece el compromiso de los Estado por hacer frente a los problemas de financiamiento para el desarrollo del mundo; en particular en los países en desarrollo. La meta externada en el consenso, es erradicar la pobreza, lograr un crecimiento económico sostenido y promover el desarrollo sustentable al tiempo que se avanza hacia un sistema económico basado en la equidad y que incluya a todos, teniendo en cuenta la Declaración del Milenio.

El llamado consenso, si bien es un buen primer paso en la materia, no implica nada más que una pieza más de soft law, pues no contiene normas de DIE vinculantes ni sancionables. Como veremos a continuación, las medidas, de convertirse en efectivas normas de DIE a través de tratados y ejecuciones razonables por parte de los gobiernos nacionales en un ambiente de real solidaridad y subsidiaridad internacionales, sin duda significarían un instrumento para el avance de la calidad de vida de muchos millones de personas en el mundo en desarrollo.

En primer lugar, el consenso busca implementar una serie de medidas para hacer realidad el financiamiento para el desarrollo. Entre las acordadas están la movilización de recursos financieros nacionales; la movilización de recursos internacionales incluidos la inversión extranjera directa y otras corrientes de capitales privados; la promoción del comercio internacional como promotor del desarrollo; el aumento de la cooperación financiera y técnica internacional; las alternativas de cara al problema de la deuda externa. Aunado a estos compromisos, el consenso dispone algunas acciones sobre cuestiones sistémicas que impiden el flujo adecuado de financiamiento para el desarrollo, y de modo específico 
el fomento de la coherencia y cohesión de los sistemas monetarios, financieros y comerciales internacionales en apoyo al desarrollo. ${ }^{70}$

Con relación al tema de la movilización interna de recursos para el desarrollo, los Estados reconocieron la necesidad de fortalecer y promover el sector financiero internacional, estimulado el desarrollo de los mercados de capital por medio de sistemas bancarios sólidos y otros mecanismos institucionales destinados a atender las necesidades de financiamiento para el desarrollo, en particular el sector de los seguros y los mercados de bonos y valores, que promueven y canalizan el ahorro y fomentan las inversiones productivas. Sin duda, para alcanzar estos objetivos, se requiere - de acuerdo al Consenso de Monterrey - de un buen sistema de intermediación financiera, marcos reglamentarios transparentes y mecanismos de supervisión eficaces, respaldados por un banco central sólido. ${ }^{71}$

Al menos como un primer peldaño, parece interesante observar cómo en el ámbito de la movilización internacional de recursos, los países signatarios del Consenso de Monterrey manifestaron su apoyo a la creación de nuevos mecanismos de financiamiento en los que participen los sectores público y privado, y en que se utilicen instrumentos de deuda y valores, tanto en los países desarrollados como en los países con economías en transición, y que beneficien en particular, a los pequeños empresarios, las empresas pequeñas y medianas y los servicios de infraestructura. ${ }^{72}$

Otro punto de interés es el relativo a la deuda externa. Respecto a este espinoso tema, en Monterrey se logró acordar que su alivio puede ser un factor crítico para liberar recursos que pueden entonces encauzarse hacia actividades que promuevan un crecimiento y desarrollo sustentables e invitó activamente y sin mayores tardanzas, una decisión al respecto por asociaciones relevantes de acreedores como los clubes de París y Londres. Más aún, en un intento por flexibilizar las posiciones del FMI y el Banco Mundial en materia crediticia, se acordó la necesidad de que éstos, al formular recomendaciones sobre cuestiones normativas y, en particular, cuando corresponda sobre el alivio de la deuda, tengan en cuenta cualquier cambio que haya alterado de manera fundamental, la sustenta- 
bilidad de la deuda de un país, como consecuencia de catástrofes naturales, trastornos graves de la relación de intercambio o conflictos. ${ }^{73}$

De igual importancia nos parecen algunas de las medidas acordadas sobre la coherencia y cohesión entre los sistemas monetario, financiero y comercial para el apoyo al desarrollo. En particular la prioridad para el Fondo Monetario Internacional en prevenir posibles crisis y en fortalecer los cimientos de la estabilidad financiera internacional. En este sentido, el fondo debe reforzar más sus actividades de vigilancia de todas las economías, prestando especial atención a las corrientes de capitales a corto plazo y sus consecuencias. Con ello, la Cumbre de Monterrey exhortó al FMI a establecer un sistema de vigilancia y alerta temprana bien estructurados para facilitar la detección oportuna de síntomas de vulnerabilidad externa y a que coordine estrechamente su labor con las instituciones $u$ organizaciones regionales pertinentes, incluidas las comisiones regionales de las Naciones Unidas.

En este mismo sentido, se acordó la necesidad de que las instituciones financieras multilaerales, al proporcionar asesoramiento sobre cuestiones normativas y apoyo financiero, tomen como base los programas nacionales de reforma que estén bien fundados y con los cuales se haya identificado los países respectivos, que tengan en cuenta las necesidades de los pobres e incluyan medidas para reducir la pobreza. De igual manera, esas instituciones deben tomar en consideración las necesidades especiales y la capacidad de ejecución de los países en desarrollo y los países en economías de transición con miras a fomentar el crecimiento económico y el desarrollo sustentable. Al prestar tal asesoramiento - señala el consenso- deben tener presentes los costos sociales de los programas de ajuste, que deberían diseñarse de manera de reducir al mínimo sus repercusiones negativas en los segmentos vulnerables de la sociedad.

Un paso más en formular un DIE más justo en el terreno del financiamiento para el desarrollo, es como expresa el Consenso de Monterrey, asegurando la participación eficaz y equitativa de los países en desarrollo en la formulación de normas y códigos financieros; asegurando el cumplimiento de éstos de manera progresiva y voluntaria, a fin de reducir la

73 Ibidem, p. 50. Si bien el consenso reconoce que es necesaria una combinación flexible de instrumentos para tener en cuenta adecuadamente las circunstancias económicas y capacidades de los países, destacó la importancia de establecer un conjunto de principios claros de gestión y solución de crisis financieras que prevea una distribución equitativa de la carga entre el sector público y el privado, y entre deudores, acreedores e inversionistas. 
vulnerabilidad de los países a las crisis financieras y al efecto de contagio. ${ }^{74}$ Hasta aquí pues nuestra introducción a la Cumbre de Monterrey sobre financiamiento para el desarrollo. Volveremos desde otros ángulos a ella, cuando ahondemos en el FMI y el Banco Mundial como cauces institucionales del ámbito financiero del DIE.

\section{Efectividad y desarrollo sustentable: tercer eslabón en la lucha por el compromiso}

Una de las reuniones internacionales que ha tenido mayor impacto en el terreno declarativo para el desarrollo sustentable — por la institución de la cual proviene- es la Declaración de la Conferencia Ministerial de la OMC de Doha de 2001. En realidad, la Conferencia de Doha se convirtió en un catalizador importante de la Cumbre de Johannesburgo, y es por ello importante marcarla como una referencia.

Pues bien, a raíz de fuertes críticas al sistema de la OMC, particularmente las formuladas en el contexto de la Conferencia Ministerial de Seattle, la Conferencia de Doha reconoció una serie de exigencias del desarrollo sustentable. Este reconocimiento parece representar un rechazo a la idea de que las normas de DIE, en especial las de comercio internacional, no deben estar influenciadas ni contener aspectos distintos a los propiamente comerciales. ${ }^{75}$

Así, en Doha si bien sólo a nivel declarativo - clara presencia del soft law de nuevo- se reconoció que en virtud de las normas de la OMC no debe impedirse a ningún país que adopte medidas para la protección de la salud y la vida de las personas y los animales o la preservación de

74 Ibidem, p. 57. Una exigencia más acordada por el consenso para los organismos financieros es que éstas cuenten con un conjunto adecuado de servicios y recursos financieros para responder oportunamente y en forma apropiada, de conformidad con sus respectivas políticas. Además, las líneas de crédito para imprevistos son un importante indicador de la fortaleza de las políticas nacionales y una salvaguardia contra el contagio en los mercados financieros. Un mecanismo relevante en materia estabilizadora de los fondos de reserva regionales y subregionales, las disposiciones sobre swaps y mecanismos análogos que complementan la labor de las instituciones financieras. Véase, además, Loibl, Gerhard, "The World Bank Group and sustainable development", en varios autores, International Economic Law with human face..., cit.; Denters, Erik, Financing the protection..., cit.

75 Sobre análisis y críticas a la Conferencia Ministerial de Doha, véase en general Lal, Bhagirath, WTO: the Doha Agenda: the new negotiations on world trade; TWN, 2003; Buckley, Ross (ed.), The WTO and the Doha Round: the changing face of world trade (global trade and finance), La Haya, Kluwer, 2003; Hoekman, Bernard, The Doha round and the WTO: a new agenda for development, Washington, World Bank Publications, 2005. 
los vegetales, o para la protección del ambiente a los niveles que se consideren apropiados, a reserva que esas medidas no se apliquen de manera que constituya un medio de discriminación arbitrario o injustificable entre países en que prevalezcan las mismas condiciones; o una restricción encubierta del comercio internacional. ${ }^{76}$

Dentro de su programa de trabajo, en la Conferencia de Doha, además de los temas ordinarios de la agenda de la OMC, acordó mecanismos de comunicación para que los instrumentos ambientales internacionales sean realmente tomados en consideración en las deliberaciones sobre comercio. En este sentido, la conferencia requirió a su Comité de Comercio y Medio Ambiente que, al proseguir con los puntos de su propia agenda, tuviera particular atención en el efecto de las medidas ambientales en el acceso a los mercados, especialmente en relación con los países en desarrollo menos adelantados; así como en las situaciones en que la eliminación o reducción de las restricciones y distorsiones del comercio puedan beneficiar al ambiente y al desarrollo. ${ }^{77}$

Hecho el anterior comentario sobre la influencia de la Conferencia de Doha de la OMC en su similar de la ONU en Johannesburgo, debemos indicar que en preparación para la Cumbre de Desarrollo Sustentable, el secretario general de la ONU, Kofi Annan, tomó en consideración el Consenso de Monterrey sobre Financiamiento para el Desarrollo, alcanzado apenas cinco meses; esto con el fin de subrayar las prioridades sobre desarrollo sustentable. En un exhorto a los gobiernos participantes en Johannesburgo, el secretario general puso de manifiesto su decepción por el escaso éxito alcanzado a diez años de la Cumbre de la Tierra de Río en 1992 sobre la misma materia, y urgió a las delegaciones a llegar al menos a cumplir cinco metas muy concretas, vinculadas además de modo estrecho con los Objetivos de la Declaración del Milenio y a sus plazos de cumplimiento. Las metas sugeridas por el secretario general quedaron planteadas del siguiente modo:

- Agua y saneamiento: poner el agua al alcance de por lo menos mil millones de personas que carecen de agua apta para el consumo y proveer de saneamiento adecuado a dos mil millones de personas.

76 OMC, WT/MIN(01)/DEC/1, pp. 6 y ss.

77 Ibidem, pp. 31 y ss. 
- Energía: dar acceso a la energía a dos mil millones de personas que carecen de servicios modernos de ésta; promover las fuentes de energía renovables; reducir el consumo excesivo; y ratificar el Protocolo de Kyoto (a la Convención Marco de las Naciones Unidas sobre el Cambio Climático de 1992) para abordar la cuestión del cambio climático.

- Salud: abordar los efectos de los materiales tóxicos y peligrosos; reducir la contaminación del aire, que mata a tres millones de personas todos los años, y la incidencia del paludismo y la dracunculosis, ambos padecimientos asociados con el agua contaminada y la falta de saneamiento.

- Productividad agrícola: trabajar para revertir la degradación de las tierras, que afecta a aproximadamente dos tercios de las tierras agrícolas del mundo.

- Diversidad biológica y ordenación de los ecosistemas: revertir los procesos que han destruido aproximadamente el 50\% de la selva pluvial y los manglares de la Tierra; amenazan al 70\% de los arrecifes de coral y han diezmado las pesquerías.

Con esta tarea encomendada por el secretario general para hacer de la Cumbre de Johannesburgo un puente entre las aspiraciones y la realidad, veremos ahora en términos generales lo debatido y decidido. Si bien las resoluciones y las medidas de implementación — al igual que el caso del Consenso de Monterrey y muchos otros del DIE - pueden ser consideradas soft law, lo cierto es que marcan una perspectiva de desarrollo sustentable a otros instrumentos normativos del DIE que efectivamente constituyen hard law - convenios multilaterales y bilaterales en materia de comercio, inversiones, financiamiento público, competencia económica, aspectos mercantiles de la propiedad industrial, trato preferente, etc- - Esto es, tratados internacionales y mecanismos de solución de controversias mediante los cuales se contienen normas vinculantes y mecanismos efectivos de sanción por incumplimientos.

Pues bien, en Johannesburgo se adoptaron dos resoluciones de importancia para el tema. La primera, llamada Declaración de Johannesburgo sobre el Desarrollo Sostenible representa el instrumento de corte político internacional; la segunda establece el plan de aplicación de las decisiones de la cumbre y posteriormente fue recomendada a la Asamblea General de la ONU para su aprobación, lo cual ocurrió unos meses 
después en Nueva York. Tras una serie de manifestaciones emotivas características de este tipo de documentos, la Declaración reconoce que la humanidad se encuentra en una encrucijada a partir de la cual, los países participantes responden con la formulación de un plan práctico y concreto que permita erradicar la pobreza y promover el desarrollo humano; $;^{78}$ veamos a grosso modo sus contenidos, pues como hemos dicho, significan — pese a su imperfección natural por no ser vinculantes - fuente y perspectiva real del DIE. ${ }^{79}$

El Plan de Aplicación de las Decisiones de la Cumbre Mundial sobre Desarrollo Sostenible de 2002, además de una introducción explicativa está compuesto por diez capítulos, entre los cuales destacan: la erradicación de la pobreza; modificación de las modalidades insostenibles de consumo y producción; protección y gestión de la base de recursos naturales del desarrollo económico y social; desarrollo sostenible para África; medios de ejecución; y marco institucional para el desarrollo sustentable. ${ }^{80}$

Si bien a simple vista, las medidas podrían parecer no mucho más que retórica de políticos que aprovechan el reflector internacional de unos días para ganar adeptos dentro de sus electorados nacionales; lo cierto es que lo propuesto en Johannesburgo es la base, el marco mundial generador de políticas públicas, a partir del cual, se concreta la cooperación internacional en materia económica —uno de los contenidos del DIE - con recursos financieros reales, transferencia de tecnología, inversión, etcétera. Con esto en mente, resulta interesante advertir cómo la cumbre entiende la interacción entre globalización económica y desarrollo sustentable.

En palabras de los países participantes, se reconoce que la globalización y la interdependencia ofrecen nuevas oportunidades para el comercio, las inversiones y las corrientes de capital, así como para el avance de

$78 \mathrm{Al}$ inicio de la cumbre, niños de todo el mundo, con palabras sencillas y claras pidieron a los representantes hacer lo posible para que ellos puedan heredar un mundo libre de las indignidades y ultrajes que engendran la pobreza, la degradación ambiental y el desarrollo insostenible. Véase A/CONF.199/20.

79 Véase Russel, Trevor, World Summit on Sustainable Development, Greener Management International, 39, 2002; Flavin, Christopher, Climbing a sep summit, Worldwatch Institute, 2002; Engfeldt, Lars, The road from Stockholm to Johannesburg. Achievements in sustainable development, N. Y., Publicaciones de la ONU, 2002; Pring, George, "The 2002 Johannesburg World Summit on sustainable development: International Environmental Law collides with reality, turning Jo'burg into 'joke burg'... enver", Journal of international Law and Policy, Denver, 2002.

80 Ibidem, véase en especial párrafos 7-13; 14-23; 24-46; 67-71; 81-136; y 137-170. 
la tecnología - incluida la de la información - y contribuyen al crecimiento de la economía mundial, el desarrollo y el mejoramiento del nivel de vida en todo el mundo. No parece pues, haber una oposición de carácter globalofóbica en la cumbre. Sin embargo - sigue el reporte- al mismo tiempo sigue habiendo graves desafíos, incluidas graves crisis financieras, inseguridad, pobreza, exclusión y desigualdades dentro de las sociedades y entre ellas. Entre las medidas suaves - soft law - acordadas, se puede advertir la interacción entre los contenidos de Monterrey, Doha y Johannesburgo a partir de lo originalmente expresado en Río.

Así, se propone en primer lugar, seguir promoviendo sistemas comerciales y financieros multilaterales abiertos, basados en normas previsibles y no discriminatorios. Se pretende apoyar la conclusión satisfactoria del programa de trabajo de la Declaración Ministerial de Doha y del Consenso de Monterrey. Respecto a la primera, se acoge positivamente su decisión de situar las necesidades e intereses de los países en desarrollo en el centro del programa de trabajo, intensificando con ello el acceso a los mercados de los productos de interés para los países en desarrollo. ${ }^{81}$ La dimensión privada en el DIE — otra de las discusiones de filosofía normativa de la disciplina - no fue la excepción en las medidas adoptadas, y en ese sentido se acordó promover activamente la responsabilidad y la rendición de cuentas en las empresas.

En un afán por especificar programas de acción eficaces a nivel regional, la cumbre a partir de los datos arrojados para el diseño de los Objetivos del Milenio, decidió darle un tratamiento especial a África y por ello se acordaron algunas medidas pragmáticas que tienen su fundamento en la llamada Alianza de la ONU para África, que es una de las derivaciones del Programa 21 generado con motivo de la Declaración de Río. Bajo este contexto, los países participantes se comprometieron en apoyar los esfuerzos en pro de la paz, la estabilidad y la seguridad, la solución y prevención de conflictos, la democracia, la buena gestión de los asuntos públicos, el respeto de los derechos humanos y las libertades

81 Ibidem, p. 47. Resulta interesante como tras una insistencia de ya varios años — sostenida fundamentalmente en la Conferencia Ministerial de la OMC en Seattle - el tema de la transparencia en la negociación internacional ha encontrado un buen cauce. Así, se acuerda velar porque los países en desarrollo participen de forma significativa, eficaz y plena en las negociaciones multilaterales, situando sus necesidades e intereses en el centro del programa de trabajo de la OMC. 
fundamentales, incluido el derecho al desarrollo y la igualdad de géneros. ${ }^{82}$

Entre las medidas de naturaleza económica se acordó fomentar la productividad, diversidad y competitividad de la industria de los países africanos, mediante una combinación de apoyo financiero y tecnológico para el desarrollo de infraestructura fundamental; acceso a tecnología; y establecimiento de contactos entre centros de investigación; la adición de valor a los productos de exportación; el desarrollo de aptitudes y el aumento del acceso a los mercados en apoyo del desarrollo sustentable.

En uno de los temas más urgentes para la región - $\mathrm{y}$ de mayor inequidad social en la historia de la humanidad - el del acceso a la salud, se acordó movilizar apoyo financiero y de otra índole para promover la igualdad de acceso a estos servicios; brindar acceso a los medicamentos y tecnologías necesarios de forma sostenible y asequible para combatir y controlar enfermedades contagiosas como el VIH-SIDA, el paludismo, la tuberculosis y la tripanosomiasis, así como enfermedades no contagiosas, incluidas las causadas por la pobreza. Se convino además en la necesidad de utilizar los citados recursos financieros y de otra índole para aumentar la capacidad del personal médico y paramédico; la promoción de los conocimientos médicos autóctonos; así como la investigación y combate a la enfermedad del Ébola.

Sin duda, el diseño y buena gestión institucional para el desarrollo sustentable es uno de los retos más grandes para dar efectividad a los propósitos de conjunto integrado por los contenidos de las cumbres de Río, Monterrey, Doha, Johannesburgo y otras de igual importancia. Para facilitar esta efectividad en el ámbito de la ONU, se ha dispuesto de un marco institucional basado en el Programa 21 que tiene como misión aglutinar de modo coordinado a todos los niveles jerárquicos de decisión; de modo que los acuerdos tengan un flujo transparente y sencillo de cumplimiento, no sólo en el ámbito multilateral, sino también en el nacional.

La tarea de coordinación más importante tanto al interior del sistema de la ONU en materia de desarrollo sostenible —en particular con el PNUD y otros organismos especializados - como entre los países y las

82 Como puede advertirse, el contenido de derecho internacional humanitario y de índole social mínimo es la plataforma básica para concretar el desarrollo sustentable en África. Algunos de sus problemas contemporáneos a partir de una exclusión milenaria puede verse en Nugent, Paul, $A f$ rica since independence, Nueva York, Palgrave, 2004, p. 434. 
ONG es la de la Comisión para el Desarrollo Sustentable. La comisión está concentrada en la División de la ONU para el Desarrollo Sustentable y reporta al Ecosoc. La comisión fue creada por el Programa 21 a partir de la Declaración de Río y existe desde diciembre de 1992. Como señalábamos antes, tiene en su agenda anual el monitoreo y reporte de los logros y retos en la implementación de los acuerdos sobre desarrollo sustentable del Programa 21 y los matices a éste implementados en Johannesburgo. ${ }^{83}$

\section{COMENTARIOS FINALES}

La dinámica de las relaciones internacionales contemporáneas parece haber colocado al DIE en el centro del DIP. Las negociaciones sobre liberalización de comercio y servicios en la $\mathrm{OMC}$; la renovación de las condiciones crediticias del BM; o los esfuerzos por concretar mecanismos sólidos de cooperación por el PNUD son, como hemos sugerido, solo algunos ejemplos de la importancia que ha adquirido la disciplina.

Este acelerado crecimiento en la producción normativa de los instrumentos del DIE, sin embargo, corre el riesgo de hacer del DIE, un mero cauce formal de los flujos económicos. Desde nuestro punto de vista, su objeto no debe disociarse de los valores que estructuran al derecho; sino por el contrario, nutrirse de ellos.

En este contexto, el único camino para que el DIE no pierda su rumbo como promotor de valores universales, es el de la auténtica receptividad a las perspectivas plurales que de él se tengan. En este ejercicio, la sociedad civil y en particular, la comunidad académica tienen una grave responsabilidad.

La modesta aportación que este trabajo pretende ofrecer, consiste en unir el bolígrafo a aquel de quienes denuncian la urgencia por dotar al DIE de un sentido humanista; y desde esa trinchera, ayudar en la construcción de alternativas viables a la agenda económica de la comunidad internacional. 